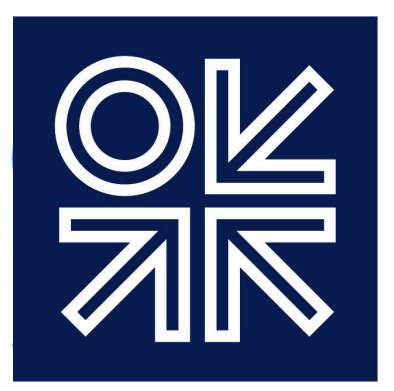

THE OXFORD

INSTITUTE

FOR ENERGY

STUDIES

June 2018

\title{
A review of demand prospects for LNG as a marine transport fuel
}

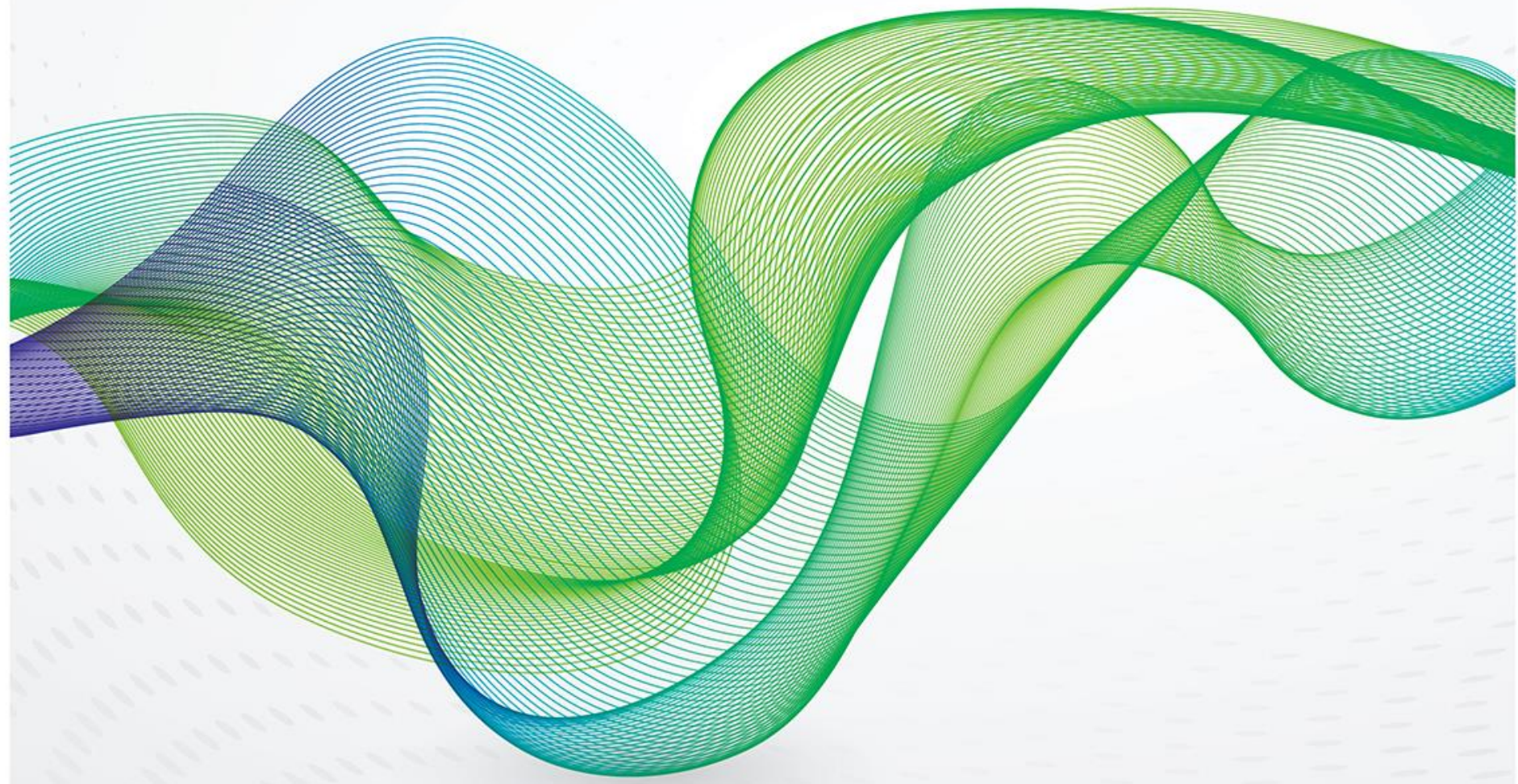


The contents of this paper are the author's sole responsibility. They do not necessarily represent the views of the Oxford Institute for Energy Studies or any of its members.

\author{
Copyright $@ 2018$ \\ Oxford Institute for Energy Studies \\ (Registered Charity, No. 286084)
}

This publication may be reproduced in part for educational or non-profit purposes without special permission from the copyright holder, provided acknowledgment of the source is made. No use of this publication may be made for resale or for any other commercial purpose whatsoever without prior permission in writing from the Oxford Institute for Energy Studies.

ISBN 978-1-78467-114-3

DOI: https://doi.org/10.26889/9781784671143 


\section{Acknowledgements}

I would like to record my thanks for the help I have been given by many individuals in writing this paper. I received much valuable input from experts in the use of natural gas as a transport fuel working for sponsors of Oxford Institute for Energy Studies Gas Programme. I am also most grateful to colleagues at the OIES who have provided many valuable insights and suggestions, especially Jim Henderson, Howard Rogers and David Ledesma. I would also like to thank Liz Henderson for editing the final document and Kate Teasdale for formatting and layout. Any remaining errors are fully my own. 


\section{Contents}

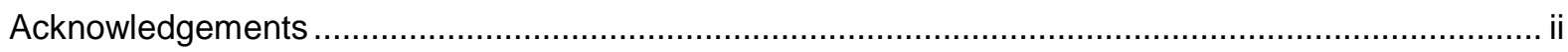

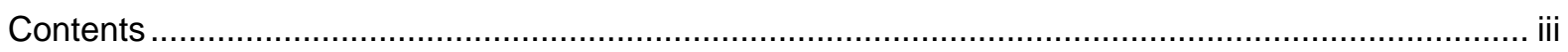

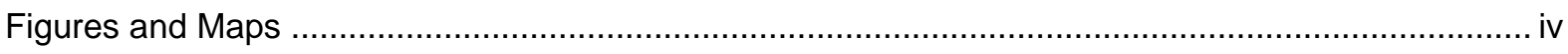

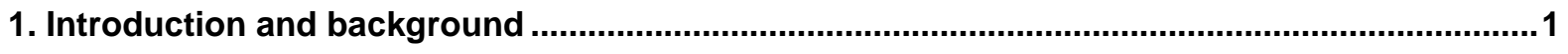

2. A review of the factors underpinning the case for LNG in transportation...............................

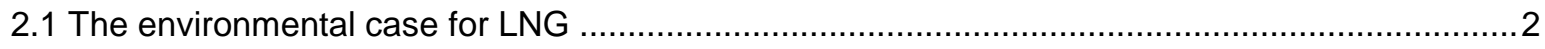

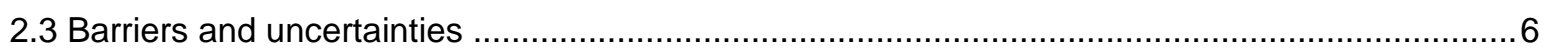

3. The global marine fuels market ..........................................................................................

4. What drives the decision to switch to LNG and in which shipping sectors is it likely? ........11

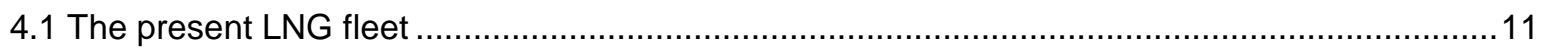

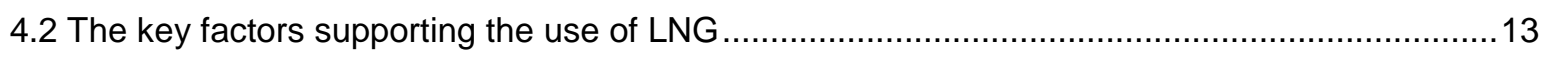

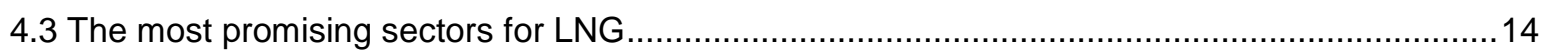

5. Forecast levels of LNG marine fuel usage .........................................................................17

6. LNG marine refuelling infrastructure .......................................................................................20

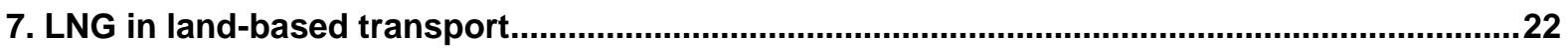

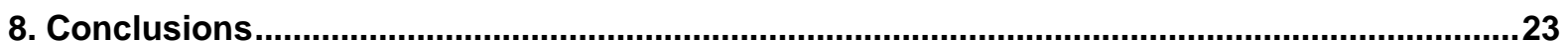

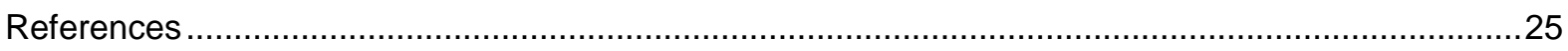

Thinkstep (2017), Greenhouse Gas Intensity from Natural Gas in Transport, A study for the Natural Gas Vehicles Association http://ngvemissionsstudy.eu/ .................................................26

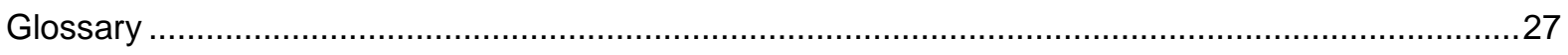

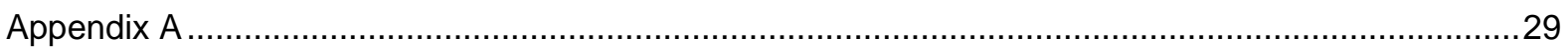

\section{List of Tables}

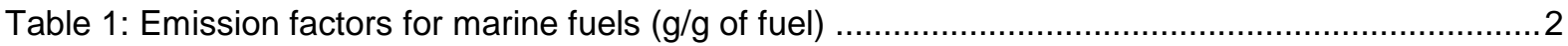

Table 2: Well-to-Wake GHG emissions for different fuels ..................................................... 3

Table 4: Global ship fuel consumption (million tonnes) ........................................................ 8

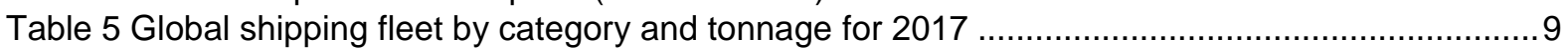

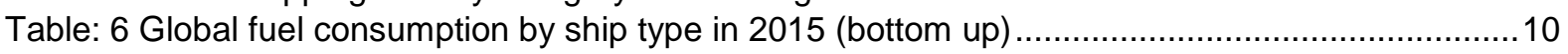

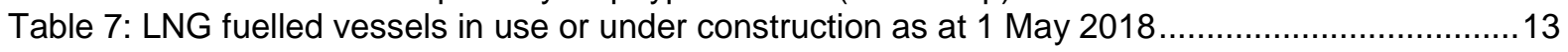

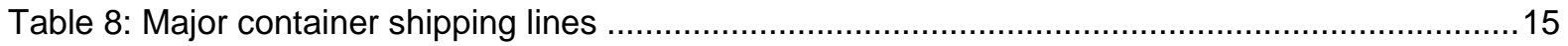

Table 9: Number of LNG vessels in operation or ordered/under construction .................................17

Table 10: Forecasts of LNG consumption in the marine sector (mtpa) ...................................... 18

Table 11: LNG shipping new build requirement to meet 2030 forecasts of LNG consumption in the

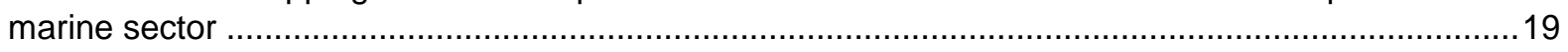

Table 12: Approximate fuel consumption for the LNG tanker fleet ........................................... 19

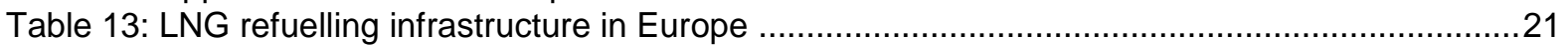

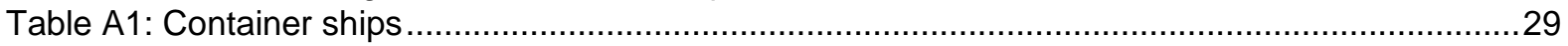

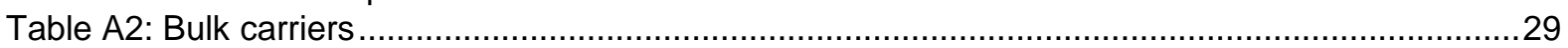

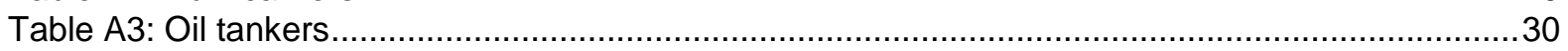

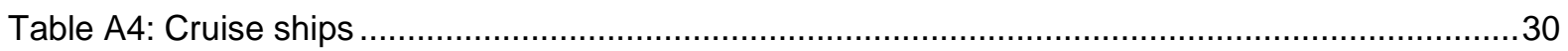




\section{Figures}

Figure 1: Total Fuel Cycle emissions per trip using modeled outputs 3

Figure 2: Marine fuel price (NW Europe) comparisons with regional gas prices ................................ 4 Figure 3: Marine fuel price differentials with regional gas prices (Negative differential means gas is cheaper)

Figure 4: Global ship fuel consumption by fuel type (million tonnes $L N G_{e q}$ ) .5

Figure 5: Percentage global fuel consumption by ship type in 2015 (based on $1 \mathrm{NG}$.................... Figure 6: LNG-fuelled vessels in use or under construction ...........................................................12

Figure 7: Number of LNG fuelled ships required to be built per annum to meet a demand level of 20 mtpa LNGeq by 2030 for "average" and "high" consumption assumptions. 


\section{Introduction and background}

In 2014, OIES published a paper on the prospects for gas in the transportation sector with particular focus on Europe. The paper concluded that prospects for gas were most promising in the marine sector where environmental restrictions were pushing ship owners and operators to consider alternatives to fuel oil.

Since then activity has certainly increased with a growing number of LNG bunkering sites and LNG fuelled vessels being built. Growing concerns over air pollution from diesel road vehicles has also given added impetus to land based applications for gas. The potential for significant volume growth in natural gas demand seems greatest in marine, although in both sectors there is still much uncertainty over pace and scale.

This study builds on the earlier report but specifically focuses on the overall prospects for LNG in marine transport. The main focus is on the marine fuels market and a separate report, to be published later in 2018, will look at the road and rail sectors for both LNG and CNG market. The reasons for treating the two markets separately are:

- Marine LNG is developing due to specific circumstances surrounding the International Maritime Organisation (IMO) restrictions on fuel oil

- The structure and operation of the marine market is very different to that pertaining in land transport

- Aside from the IMO-driven change in fuel standards the amount of state intervention in promoting alternative marine transport solutions (with one or two notable exceptions) is relatively limited. The decision to switch to LNG is therefore driven by a different set of metrics

- A decision to switch to LNG by one or two large operators could lead to a rapid and significant growth in demand that could have consequences for the global LNG market.

This paper aims:

- To assess the most promising sectors for LNG in marine transportation in global shipping markets.

- To derive a set of metrics that could be used to generate forecasts of LNG demand in the marine sector and to assess the validity of current forecasts

- To assess the current state and planned state of LNG refuelling infrastructure and its impact on market development

- To briefly mention the comparative prospects for LNG in land-based transport.

As a precursor to this, the reader is reminded of the reasons why the case for LNG's use as a transport fuel has developed.

\section{A review of the factors underpinning the case for LNG in transportation}

The advantages of LNG over other transportation fuels was covered extensively in the earlier report (Le Fevre 2013). This chapter briefly reviews these factors and updates the picture based on recent operational and commercial developments. Some of the major barriers and uncertainties to LNG adoption are also reviewed.

The two critical considerations are environmental factors and comparative fuel prices. 


\subsection{The environmental case for LNG}

Natural gas has some significant environmental advantages over traditional petroleum products. This is most notable in the use of LNG as a marine fuel rather than heavy fuel oil or marine diesel. LNG typically produces lower emissions of carbon dioxide $\left(\mathrm{CO}_{2}\right)$ and virtually no nitrogen oxides $\left(\mathrm{NO} \mathrm{O}_{\mathrm{x}}\right)$, particulate matter $(\mathrm{PM})$, or sulphur oxides $\left(\mathrm{SO}_{\mathrm{x}}\right)$. A comparison of the emission factors for marine fuels is shown in Table 1.

Table 1: Emission factors for marine fuels ( $\mathrm{g} / \mathrm{g}$ of fuel)

\begin{tabular}{|l|l|l|l|}
\hline Emission & HFO & MDO & LNG \\
\hline $\mathrm{SO}_{x}{ }^{*}$ & 0.049 & 0.003 & trace \\
\hline $\mathrm{CO}_{2}$ & 3.114 & 3.206 & 2.750 \\
\hline $\mathrm{CH}_{4}$ & trace & trace & 0.051 \\
\hline $\mathrm{NO}_{x}$ & 0.093 & 0.087 & 0.008 \\
\hline $\mathrm{PM}$ & 0.007 & 0.001 & trace \\
\hline
\end{tabular}

Source: IMO (2014)

*2012 figure based on average HFO sulphur content of 2.51 per cent

This latter feature is particularly important in the context of the IMO limits on sulphur in fuel oil. These are presently 0.1 per cent in the mandated emission control areas (ECAs) in N America and the Baltic and North Seas in Europe and 0.5 per cent globally from 2020. Today the global limit on sulphur content is 3.5 per cent and 2016 figures from the IMO show that the yearly average sulphur content of the residual fuel oils tested in 2016 was 2.58 per cent. The worldwide average sulphur content for distillate fuel in 2016 was 0.08 per cent ${ }^{1}$ so there could be significant disruption to traditional marine fuel supply chains once the new limit comes into law, impacting on fuel suppliers, traders, wholesalers, and users.

There are also $\mathrm{NO}_{\mathrm{x}}$ emissions standards for ship engines based on the year of installation on a vessel. The application of these standards is also linked to the ECAs².

The attractions of LNG in terms of reduced $\mathrm{SO}_{x}, \mathrm{Nox}$, and particulate matter are evident. LNG's advantages in terms of greenhouse gases $(\mathrm{GHG})-\mathrm{CO}_{2}$ and methane $\left(\mathrm{CH}_{4}\right)$ - are less apparent particularly when full cycle emissions and the impact of methane slip (the incomplete combustion of natural gas during the utilisation stage) are included. Methane is a much more potent $\mathrm{GHG}$ than $\mathrm{CO}_{2}$ though the methods for measuring its impact are subject to much debate ${ }^{3}$.

The full cycle effects refer to the GHG emissions resulting from moving the gas from its source to the vessel and then arising from its combustion. This approach - often referred to Well-to-Wake (WTW) emissions - captures the environmental impact of gas production, transportation, and liquefaction including the effects of methane emissions. Thomson et al (2015) have analysed the life-cycle emissions of natural gas compared to traditional petroleum-based fuels in the marine sector and the results for one of their simulations (a container ship travelling between Los Angeles and Honolulu and back) is shown in Figure 1. From this evidence it is clear that LNG's advantages in terms of air pollution $\left(\mathrm{SO}_{\mathrm{x}}\right.$ and $\left.\mathrm{PM}\right)$ are not as great when compared with other fuels with regard to overall GHG emissions. 
Figure 1: Total Fuel Cycle emissions per trip using modeled outputs

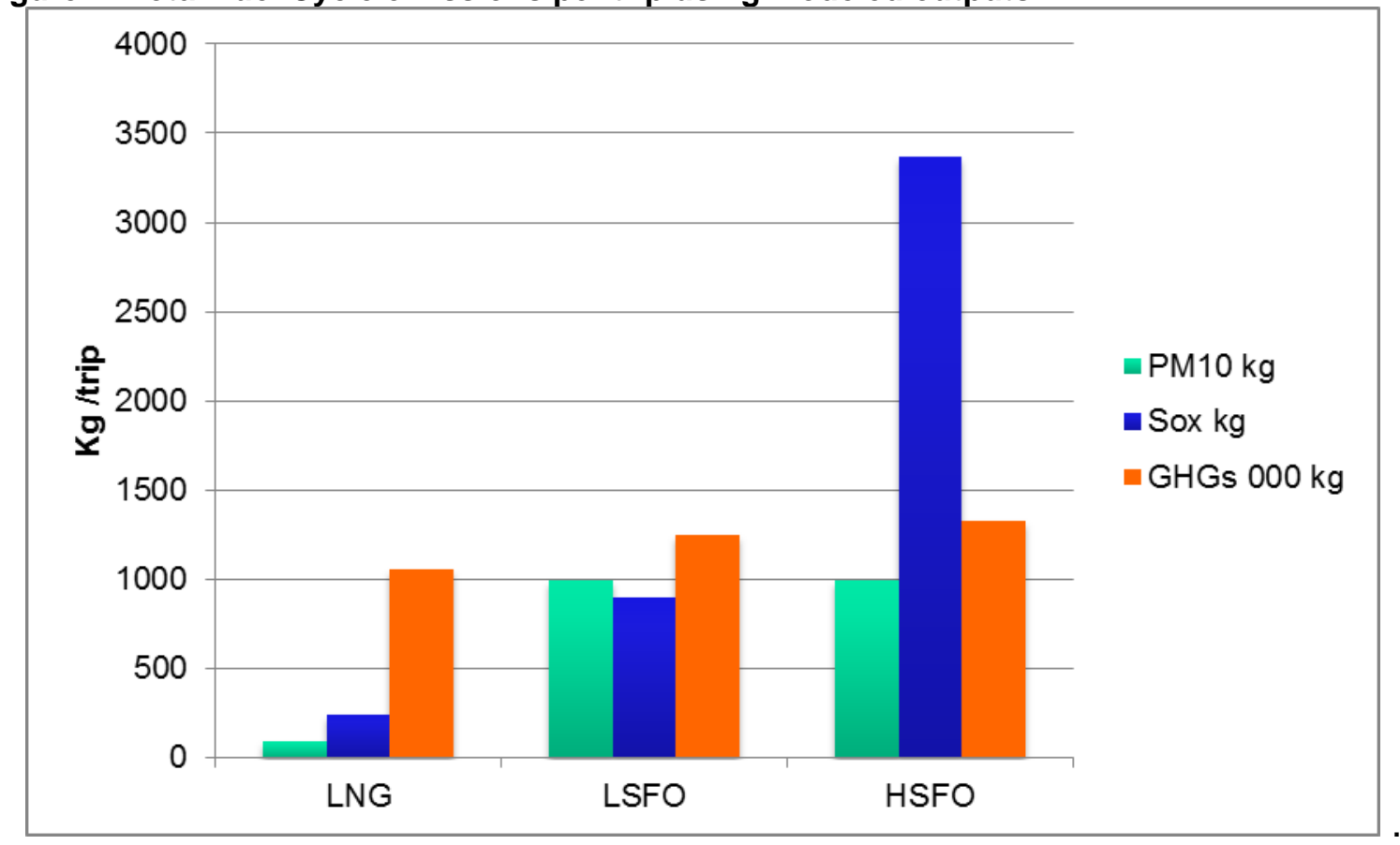

Source: Thomson et al (2015)

A more recent study by Thinkstep (2017) for the Natural Gas Vehicles Association has assessed the total WTW emissions for transport usage in the EU for both CNG and LNG. The results for LNG in marine are summarised in Table 2 showing the proportion of $\mathrm{CO}_{2}$ eq emissions that are due to methane.

Table 2: Well-to-Wake GHG emissions for different fuels

\begin{tabular}{|l|l|l|l|l|l|l|}
\hline Mode & Fuel Oil & $\begin{array}{l}\text { Marine } \\
\text { diesel }\end{array}$ & $\begin{array}{l}\text { LNG 4- } \\
\text { stroke }\end{array}$ & $\begin{array}{l}\text { Of which } \\
\text { methane }\end{array}$ & $\begin{array}{l}\text { LNG 2- } \\
\text { stroke }\end{array}$ & $\begin{array}{l}\text { Of which } \\
\text { methane }\end{array}$ \\
\hline Marine $\mathrm{CO}_{2}$ eq/kwh & 742 & 750 & 662 & 120 & 589 & 49 \\
\hline
\end{tabular}

Source: Thinkstep (2017) - Note figures for LNG are based on dual fuel engines.

One growing area of potential emissions is 'methane slip' in the transport sector where gas-fired engines are not able to fully combust all the methane which then escapes to the atmosphere. Anderson et al (2015) measured the amount of methane in the exhaust of an LNG-fuelled ferry in the Baltic Sea. This study reported around $7 \mathrm{~g}$ per $\mathrm{kg} L N G$ at higher engine loads, rising to $23-36 \mathrm{~g}$ at lower loads -0.7 per cent to 3.6 per cent. Thinkstep (2017) estimates methane slip to be in the region of $0.13-0.16$ per cent of the mass of gas consumed. The authors expect that this amount should be reduced as engine designs are adapted specifically for natural gas as a fuel ${ }^{4}$, though dual fuel engines are still likely to be susceptible to some degree of methane slip. The same study estimates methane emissions of $0.05-0.2$ per cent during fuel dispensing.

The use of biogas as a source for LNG would, of course, improve the fuel's environmental performance very significantly. Using biomass as a feedstock for LNG is a technical possibility though significant financial support is necessary. There are a small number of projects under consideration,

\footnotetext{
${ }^{4}$ The use of catalysts could significantly reduce the amount of unburned methane - see http://marigreen.eu/projects/lngmethan-catalyst-for-Ing-engines/
} 
mostly targeted at road transport ${ }^{5}$. For marine, given the volumes required there are probably other biofuel options that would be preferred.

\subsection{The economic case for LNG}

The cost of fuel is often a key consideration for ship operators and can represent between 60 and 80 per cent of total operating costs, with rising oil prices making fuel costs an even greater concern. Marine fuels are generally sold free of any tax so price comparisons are relatively straightforward though proxies have to be used for LNG as there are no published prices at present.

The most appropriate proxy for using LNG as a fuel in a particular market would be the associated trading hub: Henry Hub for east coast US, and TTF or NBP for NW Europe. The two LNG markets are different, however. In the US, the LNG price should be at a premium to $\mathrm{HH}$ as it will include the cost of liquefaction and, in circumstances when the global LNG market tightens, include a further premium reflecting this tightness (see Bros 2018). LNG prices in Europe on the other hand should, other things being equal, be at a discount to TTF or NBP as they will exclude the costs of regasification and network entry. In effect LNG users will be buying the fuel at a FOB price in the US Gulf of Mexico and a DES price at Grain or Rotterdam. For Asian markets the published imported price of LNG to Japan is probably the most appropriate proxy at the moment.

These complications may not be particularly relevant for buyers for as is noted below the trend would appear to be for sellers to offer LNG at a fixed discount to published oil product prices. Nevertheless the existence of differentials will still be important as it demonstrates that there is a margin to be exploited from shifting to LNG.

Figure 2: Marine fuel price (NW Europe) comparisons with regional gas prices

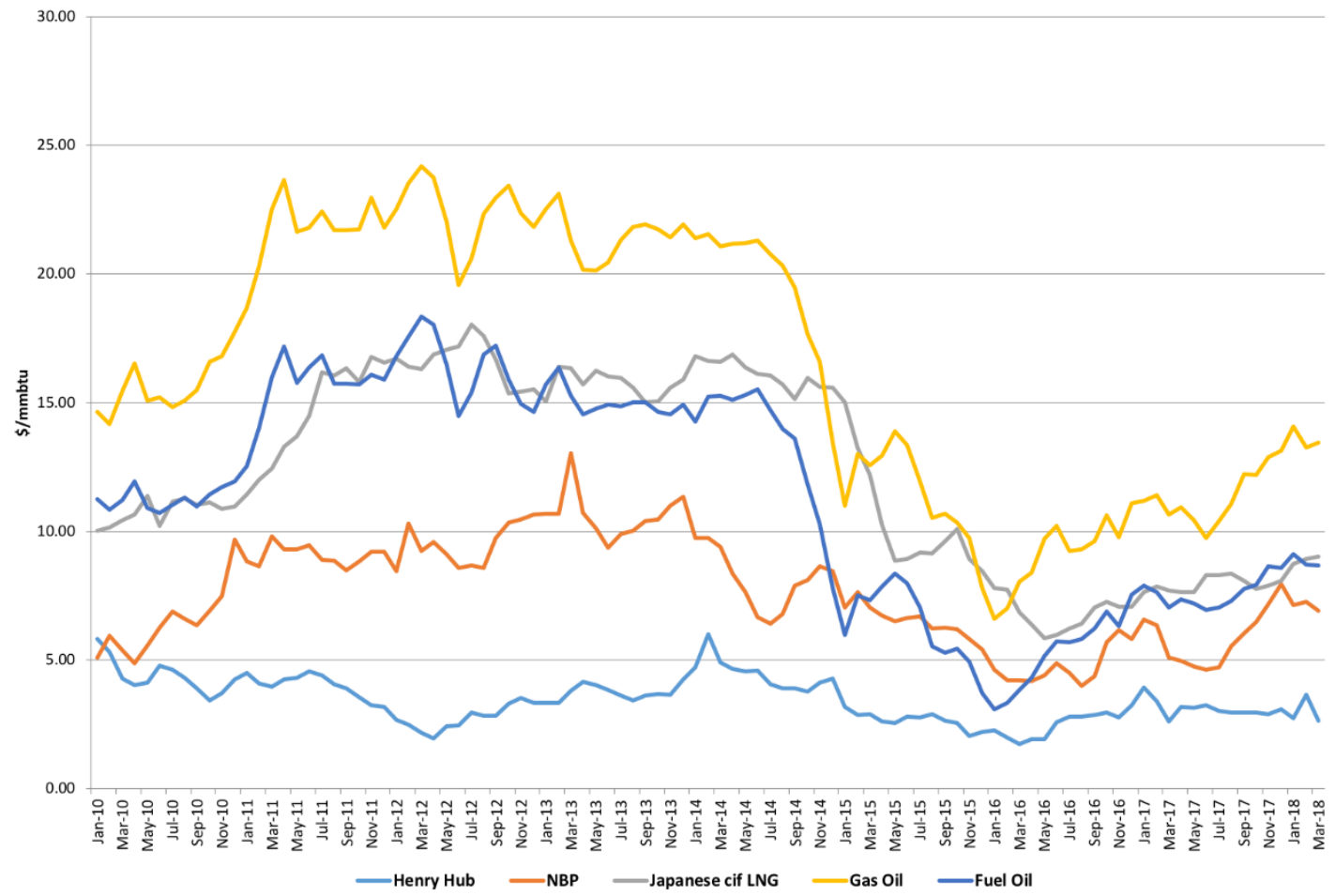

Source: Argus

${ }^{5}$ https://www.Ingworldnews.com/snam-bhge-agree-micro-Ing-infrastructure-development/ 
Figure 3: Marine fuel price differentials with regional gas prices (Negative differential means gas is cheaper)

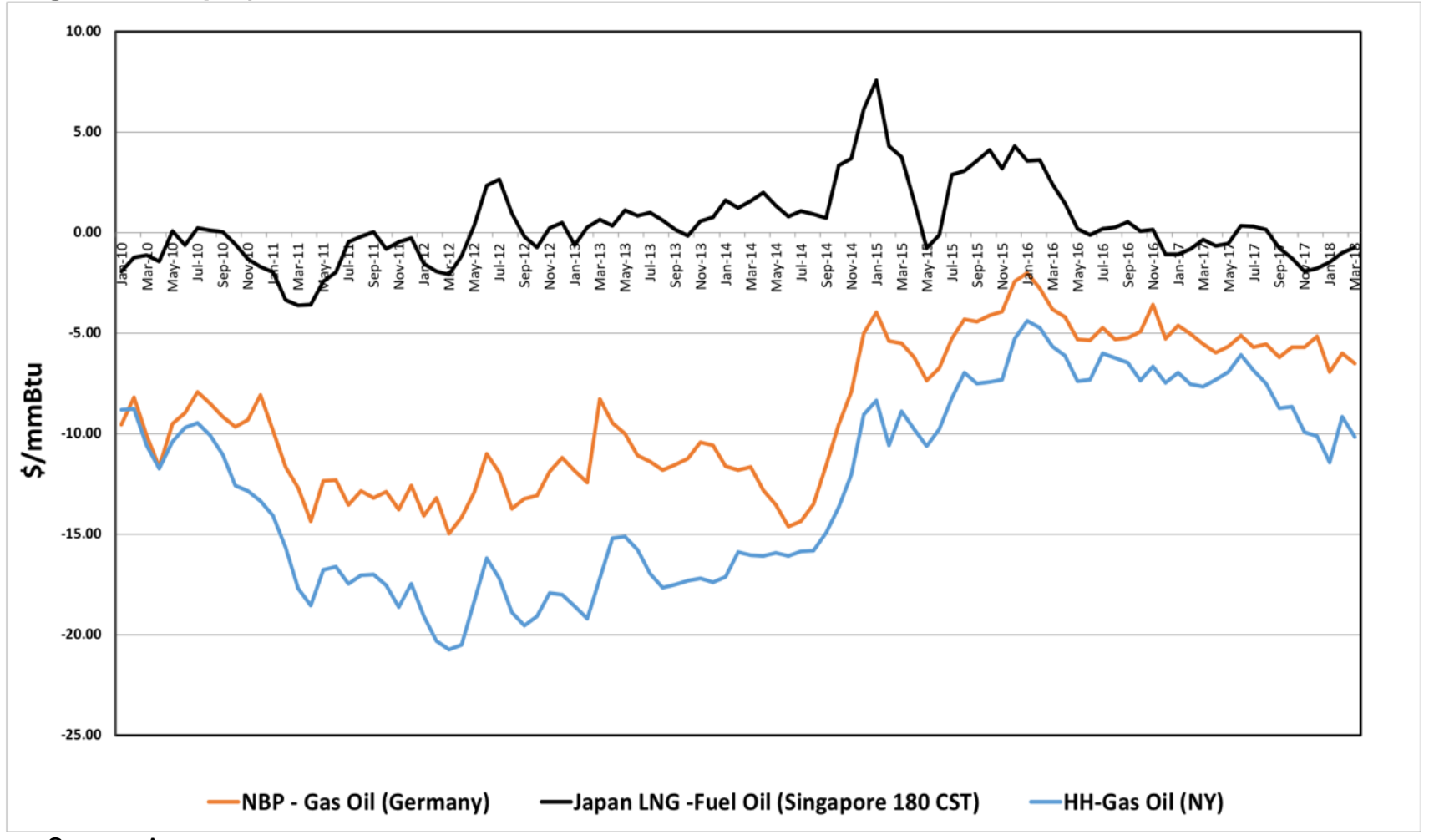

Source: Argus

Figure 2 shows the evolution of the key prices in $\$ / M M B t u$. The commodity price of natural gas has generally been cheaper than gasoil in Europe and the US whereas the differential between LNG and fuel oil in Japan is generally narrower, which is to be expected given that the price of most Japanese LNG is still linked to crude oil prices. Asian gasoil prices are typically 50 per cent higher than fuel oil prices.

Figure 3 shows the differential with gasoil in the emission control areas of North America and Europe and with fuel oil in Asian markets. The differentials have tended to narrow between 2015 and 2017 with the fall in oil prices.

Nevertheless, the discount of LNG over gas oil remains at least $\$ 5 / M M B t u$ and this is likely to be the most relevant differential once the IMO restrictions are introduced worldwide in 2020.

There are also operating cost advantages of using LNG compared to fuel oil as the cleaner fuel means that engines and associated equipment will need less maintenance and last longer ${ }^{6}$ though the cost of conversion to adapt existing vessels, estimated at around \$6 million, means LNG retrofitting is unlikely to be practical ${ }^{7}$.

There is, of course, no guarantee that existing differentials will be maintained once the IMO restrictions are introduced. The sudden excess of heavy fuel oil needing expensive sulphur-reducing treatment coupled with a shortage of diesel (Young, 2018) could lead to major and unpredictable swings in the relative spreads between gas oil and fuel oil.

\footnotetext{
${ }^{6}$ See interview with Angus Campbell of the Schulte Group in https://www.platts.com/latest-news/shipping/singapore/interview---schulte-group-sees-distillates-as-26951772

${ }^{7}$ https://www.drewry.co.uk/maritime-research-opinion-browser/maritime-research-opinions/lng-fuel-of-the-future Drewry have assumed three cases for retrofitting in the existing fleet: $5 \%, 10 \%$ and $15 \%$
} 


\subsection{Barriers and uncertainties}

Whilst LNG has some clear advantages over other fuels it is not the only solution. Ship operators looking at the alternatives to fuel oil have two other options: low sulphur marine diesel, or sulphur scrubbers with a further, as yet unpriced, possibility of low sulphur fuel oil 8 .

Whilst sulphur scrubbers may be an attractive short -term option in some circumstances, they may not represent a realistic long term option. Analysis from Drewry quotes a cost of $\$ 4$ million to install scrubbers which indicates that high sulphur fuel oil has to be at least $\$ 200 /$ tonne cheaper than 0.5 per cent low sulphur fuel oil or 0.1 per cent marine gasoil to justify the installation of scrubbers. However, there are likely to be growing restrictions on the disposal of the sulphur-rich wash water and a shortage of onshore facilities to handle it ${ }^{9}$. It is reported that a number of large shipping operators including Maersk and Teekay have already ruled out this option for this reason. Furthermore whilst the IMO has agreed to exempt vessels with scrubbers from restrictions on the transport of noncompliant fuels, local rules may make the handling and carrying of high sulphur fuels increasingly difficult and expensive. This view is borne out by the evidence that only 300 vessels had installed scrubber systems by March $2018^{10}$ although more may convert as the 2020 deadlines nears.

The shipping market is still in the doldrums with an overhang of capacity despite some recent high profile bankruptcies ${ }^{11}$. The IMO restrictions will be introduced worldwide in 2020 and this will add to the market's financial problems. Platts has estimated that a switch from fuel oil to diesel could cost a typical container fleet operator an extra $\$ 1.5$ billion annually, equivalent to an increase of $\$ 93.75 / \mathrm{TEU}^{12}$. Maersk has predicted an increase in marine fuel costs of $\$ 10$ billion for the container sector and $\$ 50$ billion for the shipping industry as a whole ${ }^{13}$. Many ship operators are reluctant to risk significant investments in this climate and have adopted a "wait and see" approach.

The prevailing commercial and regulatory framework also reinforces this conservative approach. For example, ship owners usually charter their vessels to operators and so do not benefit from any fuel cost savings from switching to LNG.

The major LNG suppliers are likely to play an important role in helping ship operators overcome the uncertainty over fuel price differentials by offering long term contracts with oil related prices. Such an approach would mean that ship operators are locking in a fixed discount to a product they are already buying whilst removing any risk associated with price spikes in the gas trading hubs. These contracts could also include guarantees regarding physical delivery which removes another uncertainty in the mind of the buyer whilst enabling the seller to recover the cost of infrastructure.

These pricing arrangements will also reduce the risk for LNG sellers, many of whom are paying for some or all of their LNG at prices linked to oil. For example, of the $21 \mathrm{BCM}$ per annum of LNG bought by Gas Natural, 7 BCM comes from the US at prices linked to Henry Hub with the remainder related to crude or oil product prices. ${ }^{14}$ Gas Natural has recently concluded a contract with ferry operator Balearia to supply LNG for eleven years. Elsewhere a major seller is understood to be offering a 30 per cent discount to MGO for some long-term agreements.

\footnotetext{
${ }^{8}$ For a comprehensive description of the alternatives available see Sharples $\mathrm{J}$, forthcoming.

${ }^{9} \mathrm{See} \mathrm{https://ec.europa.eu/transport/sites/transport/files/acceptability} \mathrm{of} \mathrm{discharges} \mathrm{of} \mathrm{scrubber} \mathrm{wash} \mathrm{water.pdf}$

${ }^{10}$ John D'Ancona of Clarksons Platou, speaking at the S\&P Global Platts 5th Annual Asian Refining Summit in Singapore, March 2018.

${ }^{11}$ Hanjin container

${ }^{12}$ Based on an operator shipping 16 million TEUs and buying 7.5 million $\mathrm{mt}$ of fuel annually, paying $\$ 200$ per ton extra for fuel. Figures quoted during Shipping and Bunker webinar, 6 September 2017.

http://s911.t.en25.com/e/er?utm campaign=17BR02EMWBPM Bunker\%20Cross\%20Sell\%20Webinar T7\&utm medium=ema il\&utm source=Eloqua\&s=911\&lid=73907\&elqTrackld=9d71225aa32d48c9b33449c214fc2675\&elq=add6a7287ec84d07bc818 cd8e60d16de\&elqaid $=45684 \&$ elqat $=1$

${ }^{13} \mathrm{https}$ ://www.platts.com/latest-news/shipping/singapore/marine-fuel-sulfur-cap-to-raise-costs-ban-non-10384957

${ }_{14}$ Article in Natural gas World, March 2018, Vol 3 ,issue 6
} 
The willingness of the gas majors to make a proactive commitment to LNG marketing is therefore an important component in overcoming some of the barriers and uncertainties. So far they appear to be adopting a range of strategies. Shell and Total have demonstrated some major commitments. Shell purchased 100 per cent of Norwegian LNG marketer GasNor in 2012 and Total has announced plans to acquire Clean Energy, a California-based LNG supplier. Total has also purchased the LNG assets of Engie, which after making much of the early running in Europe is now gradually withdrawing from the downstream LNG market. In April 2018 it sold its LNG marketing business in Belgium and the Netherlands to Titan ${ }^{15}$.

A further barrier has been the inconsistency between (and sometimes within) countries regarding the licensing and control of LNG re-fuelling. Harmonising standards and operations across all prospective markets is making progress. Organisations such as the Society for Gas as a Marine Fuel (SGMF) and SEALNG have contributed significantly to the development of standardised approaches to safe handling, custody transfer, and competency assessment ${ }^{16}$.

Nevertheless LNG is still a new fuel for many port authorities and a lack of understanding of the key differences with oil products is important. In volume terms LNG tanks need to be 80 per cent bigger than those for high sulphur fuel-oil. More crucially, as a super-cooled fuel, stored LNG will continue to evaporate until it is used. This means that it cannot be stored for extended periods without proactive management. In many ways it is more akin to a perishable product than oil. Sizing of terminals can also be quite complicated given the need to maintain sufficient reserves and heel volumes. Accordingly logistical arrangements must be organised to reflect these points and develop a comprehensive cryogenic supply chain. It will be harder to do this without a strong base-load demand ${ }^{17}$.

There is also some uncertainty over the commercial regulatory framework governing LNG infrastructure with some participants arguing that outlets should be regulated. DNV (2017) suggests that there could be many providers of LNG storage and bunkering services making the market potentially contestable. On the other hand the actual number and size of facilities may be limited, for example, due to operational or physical constraints at ports or the relatively limited extent of total demand. In these circumstances there may be a case for regulation of facilities including access and capacity allocation rules.

A final barrier for gas is that it is not a zero carbon solution unless biogas is the source. As noted above, this is unlikely to be the case for LNG though there are examples of biogas in the transport supply chain for CNG fuelled cars and trucks.

Despite these uncertainties there is a clear level of interest from a number of major ship operators in switching to LNG. In order to try and quantify what this might mean it is necessary to first gain a clearer picture of the marine fuels market.

\section{The global marine fuels market}

This chapter analyses the global marine fuels market at the existing levels and types of LNG-fuelled ships planned or in operation. It also considers typical levels of fuel usage for a variety of key vessel types. In order to provide a meaningful basis for comparison, wherever possible fuel consumption

\footnotetext{
15 https://www.Ingworldnews.com/titan-rolande-acquire-engie-Ing-

solutions/?utm_source=emark\&utm_medium=email\&utm_campaign=daily-update-Ing-world-news-2018-04-16\&uid=21190

${ }^{16}$ https://www.sgmf.info/shop

17 Some rules of thumb are a limit of 1500 nautical miles on the transportation of LNG by small tanker or 2500 km by truck

(Wartsila, 2018) and a maximum six weeks storage in smaller vessels (though in practice will probably be just one or two days).
} 

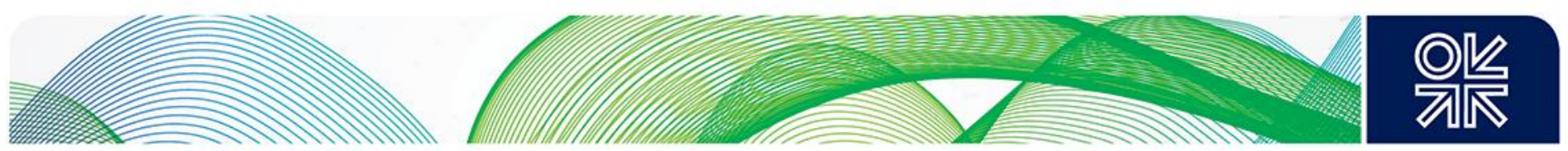

numbers have been converted to LNG equivalent (LNGeq) tonnes using appropriate conversion factors ${ }^{18}$.

Data on marine bunkers is not always accurate due to differences in data classification and collection methods. The IEA publishes global ship fuel consumption figures broken down by fuel type, for example fuel oil and marine gas oil. These numbers are based on fuel sales data. Other researchers have developed estimates of fuel consumption using the so-called bottom-up method. This approach was adopted by UCL (IMO, 2014) on behalf of the IMO to calculate $\mathrm{CO}_{2}$ emissions using Automatic Identification System (AIS) data which tracks shipping activity on an hourly basis to develop a high resolution dataset of fuel consumption ${ }^{19}$. This work was updated in 2017 in a report published by the International Council on Clean Transportation (ICCT) (Olmer et al 2017).

Both studies show that the bottom-up approach generates higher estimates of fuel consumption than that produced by the IEA. Table 4 illustrates the difference. Whilst this shows that the gap is decreasing as the accuracy of the two approaches improves, there are still some data issues and the IMO is planning a fuel monitoring exercise to identify where the gaps might lie.

The top down estimates from the IEA do not distinguish between different categories of vessels. Understanding fuel consumption by vessel type is an important consideration when determining the prospects for LNG as different sectors display very different fuel consumption characteristics. The ICCT study provides a much greater degree of granularity in terms of consumption by shipping type and so these numbers are used for the analysis in this report.

Table 4: Global ship fuel consumption (million tonnes)

\begin{tabular}{|c|c|c|c|c|c|c|}
\hline Source & Method & $\mathbf{2 0 0 7}$ & $\mathbf{2 0 0 9}$ & $\mathbf{2 0 1 1}$ & $\mathbf{2 0 1 3}$ & $\mathbf{2 0 1 5}$ \\
\hline IEA & Top down & 258 & 246 & 264 & 254 & 265 \\
\hline IMO & Bottom up & 352 & 313 & 327 & 291 & 298 \\
\hline
\end{tabular}

Source: ICCT (2017)

Figure 4 shows the breakdown of consumption by fuel category for the period from 2013 to 2015 illustrating the dominant share of fuel oil. A small amount of fuel -consumption - approximately 6.5 million tonnes - is classified as LNG of which around 97 per cent in consumed by LNG carriers, presumably in the form of boil-off gas. The following section looks at the number of vessels already using LNG.

\footnotetext{
${ }^{18}$ Where 1 tonne of LNG contains $52 \mathrm{MMbtu}, 1$ tonne of fuel oil 40.7MMbtu and 1 tonne of marine gasoil 43.3MMbtu

${ }^{19}$ For a description of how AIS works see Ricardo (2017)
} 
Figure 4: Global ship fuel consumption by fuel type (million tonnes $\mathrm{LNG}_{\mathrm{eq}}$ )

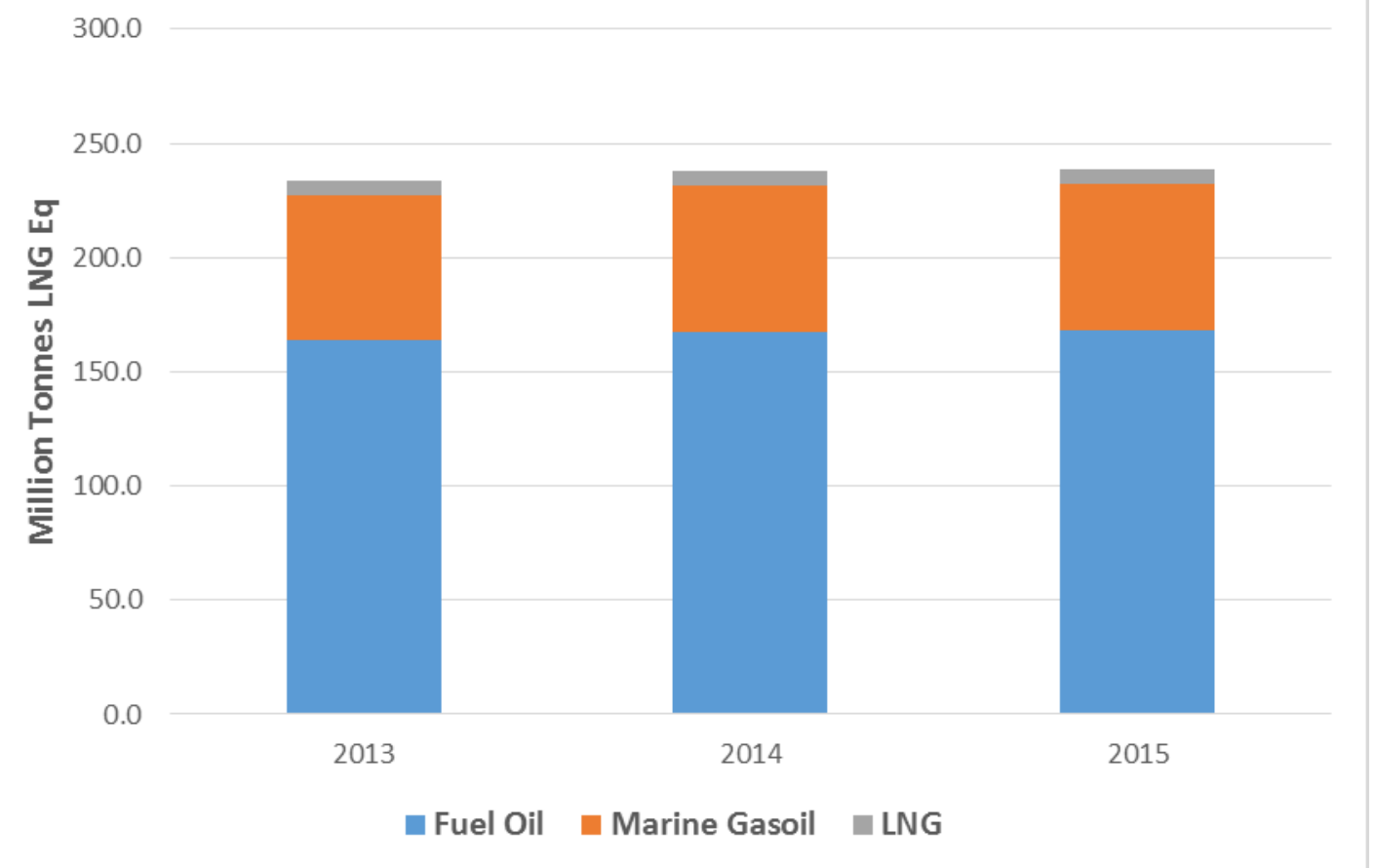

Source: ICCT

The United Nations Conference on Trade and Development (UNCTAD) classifies vessels into five principal categories:

- Oil Tankers

- Bulk Carriers

- General Cargo ships

- Container ships

- Other - this category includes gas carriers (28 per cent of DWT in this category), chemical tankers (21 per cent), offshore vessels (37 per cent), ferries and passenger ships (3 per cent) and other (11 per cent).

Table 5 shows the number of vessels by category and tonnage for 2017 .

Table 5 Global shipping fleet by category and tonnage for 2017

\begin{tabular}{|l|l|l|l|l|}
\hline Category & $\begin{array}{l}\text { Number of } \\
\text { vessels }\end{array}$ & DWT (million) & $\begin{array}{l}\text { \% of total } \\
\text { DWT }\end{array}$ & $\begin{array}{l}\text { Average } \\
\text { DWT/Vessel }\end{array}$ \\
\hline Oil Tankers & 10,152 & 535 & 28 & 52,685 \\
\hline Bulk Carriers & 10,884 & 797 & 43 & 73,188 \\
\hline General Cargo & 19,601 & 75 & 4 & 3,817 \\
\hline Container ships & 5,154 & 246 & 13 & 47,654 \\
\hline Other & 47,370 & 210 & 12 & 4,433 \\
\hline Total & $\mathbf{9 3 , 1 6 1}$ & $\mathbf{1 8 6 2}$ & $\mathbf{1 0 0}$ & $\mathbf{1 9 , 9 8 5}$ \\
\hline
\end{tabular}

Source: UNCTAD 2017 
Analysis of the detailed spreadsheets accompanying the ICCT report makes it possible to calculate fuel consumption in LNG equivalent terms and the average consumption for the different types of vessel. The following graphs and tables provide this information.

The main categories are shown in Table 6 and Figure 5 in terms of total and average fuel consumption.

Table: 6 Global fuel consumption by ship type in 2015 (bottom up)

\begin{tabular}{|l|c|c|c|}
\hline Category & $\begin{array}{l}\text { Fuel consumed (million } \\
\text { tonnes LNG eq) }\end{array}$ & $\begin{array}{l}\text { Number of } \\
\text { vessels }\end{array}$ & $\begin{array}{l}\text { Average consumption } \\
\text { (tonnes LNG eq) }\end{array}$ \\
\hline Container & 52.5 & 5,009 & 10,491 \\
\hline Bulk carrier & 43.6 & 10,650 & 4,097 \\
\hline Oil tanker & 31.6 & 6,395 & 4,938 \\
\hline Chemical tanker & 14.2 & 4,720 & 2,999 \\
\hline General cargo & 13.2 & 10,973 & 1,202 \\
\hline LPG/LNG tankers & 12.7 & 1,687 & 7,509 \\
\hline Cruise & 9.6 & 477 & 20,170 \\
\hline Ferry (ro-ro and pax) & 10.2 & 5,288 & 1,933 \\
\hline Vehicle/ro-ro & 11.4 & 2,236 & 5,658 \\
\hline Service & 8.8 & 25,317 & 397 \\
\hline Refrigerated & 3.8 & 4,876 & 779 \\
\hline Offshore & 3.5 & 785 & 4,477 \\
\hline Other + Unclassified & 23.0 & 21,021 & 1,094 \\
\hline Total & $\mathbf{2 3 8 . 1}$ & $\mathbf{9 9 , 4 3 4}$ & $\mathbf{2 , 3 9 3}$ \\
\hline Soure: ICcT (collon & & & \\
\hline
\end{tabular}

Source: ICCT (columns 1 and 2) and author's calculations (column 3) - Note conversion is on the following basis: 1 tonne of LNG contains $52 \mathrm{MMbtu}, 1$ tonne of fuel oil $40.7 \mathrm{MMbtu}$ and 1 tonne of marine gasoil $43.3 \mathrm{MMbtu}$ 

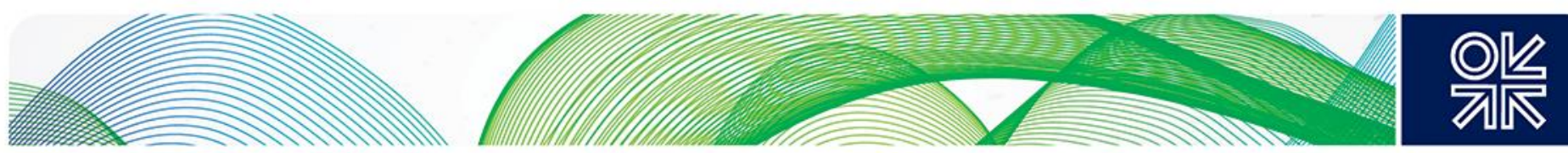

Figure 5: Percentage global fuel consumption by ship type in 2015 (based on LNG eq, bottom up)

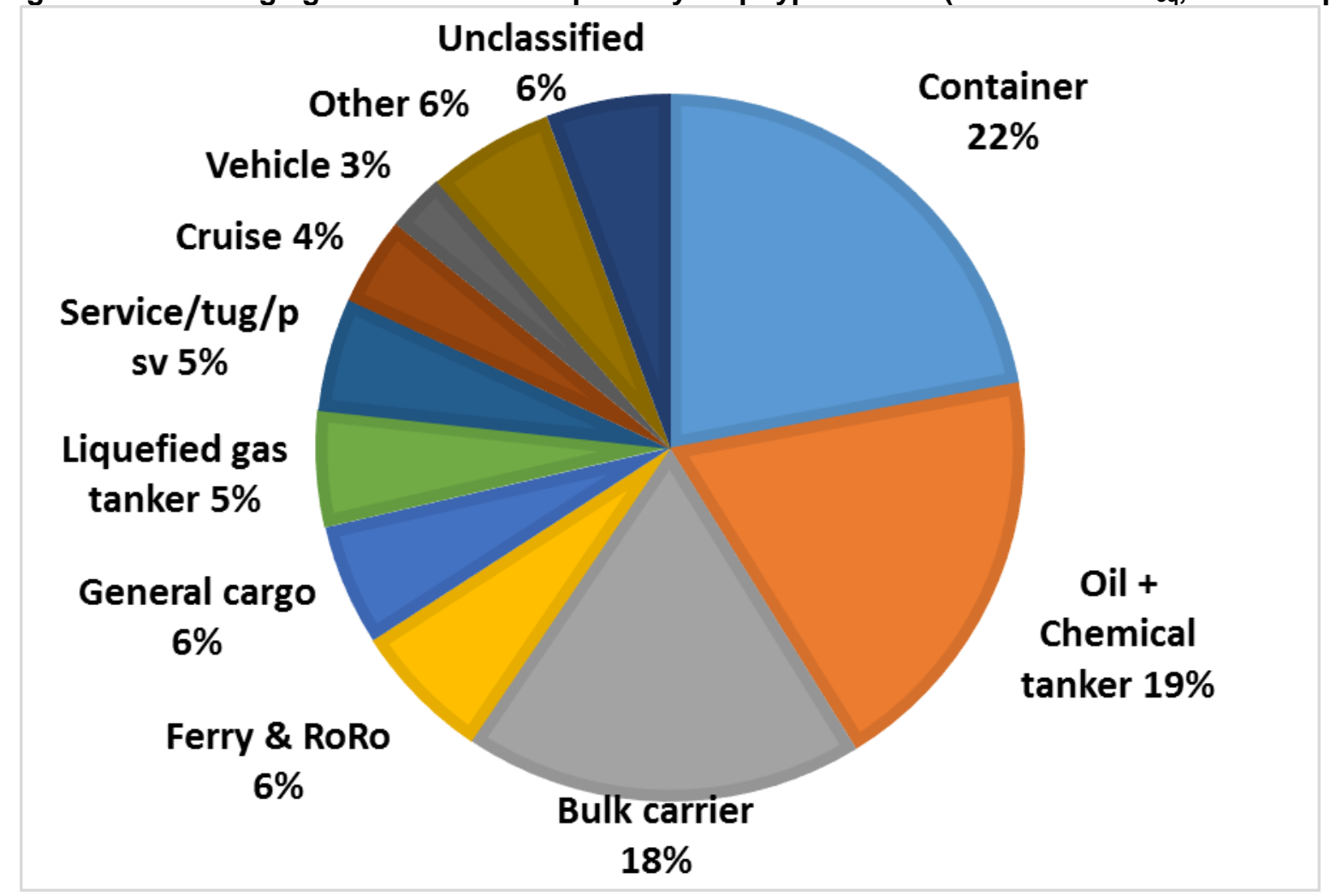

Source: ICCT and author's calculations

It is clear from Table 6 that the largest fuel consuming vessels are most likely to be oil tankers, containerships, and bulk carriers though as noted below there are some sectors in the 'other' category such as passenger ships that are of interest.

Within each sector there is a wide range of vessel types and therefore of consumption. For example there are eight different categories of container ships classified in terms of their carrying capacity in twenty-foot equivalent units (TEUs). The largest category are those ships with a capacity in excess of 14,500 TEUs. There are 68 vessels recorded on the ICCT database with an estimated average annual consumption per vessel of nearly 30,000 tonnes of LNG equivalent. Appendix 1 presents some greater detail on how consumption varies in these categories.

Fuel is not only consumed for propulsion but also for auxiliary engines. These vary by vessel category: for bulk carriers 84 per cent of consumption is for the main engine, while for cruise ships it is only 76 per cent. (Ricardo 2017).

\section{What drives the decision to switch to LNG and in which shipping sectors is it likely?}

\subsection{The present LNG fleet}

There are a number of LNG-fuelled vessels (other than LNG carriers) already in operation or on order. In gross tonnage terms the share of LNG-capable vessels delivered has grown from 1.4 per cent in 2010 to 5.7 per cent in 2017 (UNCTAD, 2017). This proportion rises to 13.5 per cent for those vessels ordered and due to be delivered from 2018 onwards. 

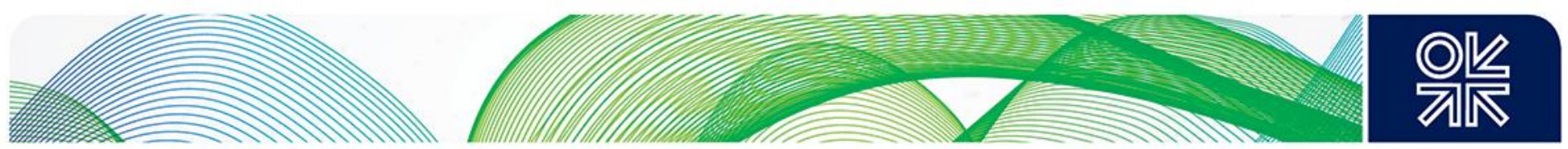

Figure 6: LNG-fuelled vessels in use or under construction

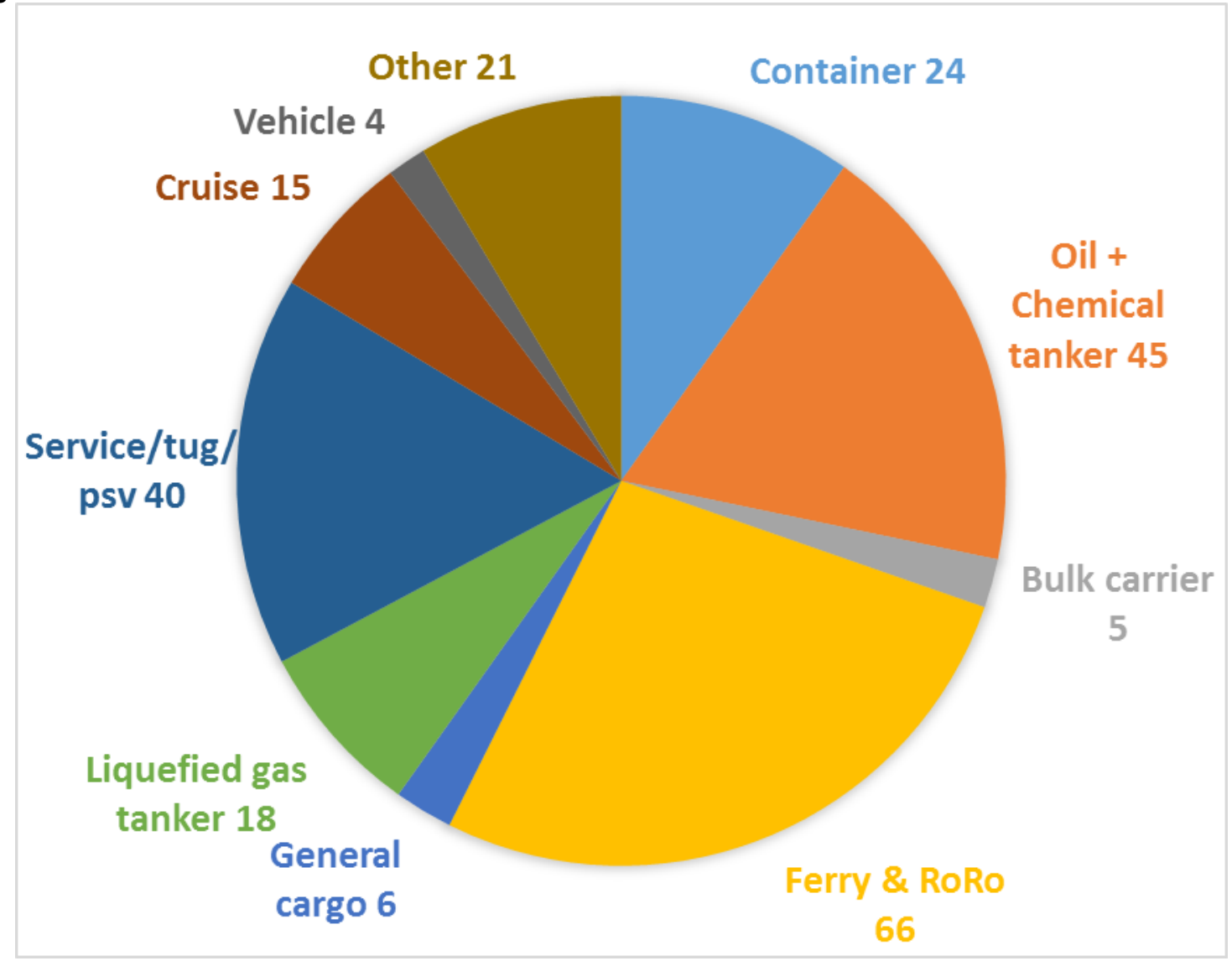

Source DNV, 2018

According to DNV statistics, as at 1 May 2018 there were 122 LNG-fuelled ships in operation and 132 in construction or confirmed orders. The breakdown of these numbers by category is shown in Figure 6 and Table 7 with the latter providing some indicative fuel consumption numbers based on the ICCT averages. Average numbers for the four shipping categories (container ships, oil and chemical tankers, cruise ships, and ferry/ro-ro vessels) with the largest potential consumption have been split to show the average consumption across all ship sizes, and average consumption if only the larger vessel sizes are used. So for example in the case of container ships, average LNG consumption is 10,491 tonnes of $L N G_{\text {eq }}$ per annum if all vessel sizes are included. This average increases to 25,388 tonnes of LNG eq per annum if only vessels with a size in excess of 12,000 TEU are assessed. The potential LNG consumption from those vessels in operation and under construction is therefore assessed to be in the range of 1.3 to 3.0 million tonnes of $L N G_{\text {eq }}$ per annum. It should be noted that these numbers exclude conventional LNG carriers and the liquefied gas tankers in the table refer to multi-purpose product carriers ${ }^{20}$ primarily operating in the Baltic and North Sea.

\footnotetext{
${ }^{20} \mathrm{See}$ https://evergas.net/fleet/fleet-list-overview/ for examples of the type of ships
} 
Table 7: LNG fuelled vessels in use or under construction as at 1 May 2018

\begin{tabular}{|l|l|l|l|l|}
\hline & $\begin{array}{l}\text { In } \\
\text { Operation }\end{array}$ & $\begin{array}{l}\text { Under } \\
\text { construction }\end{array}$ & $\begin{array}{l}\text { Proportion } \\
\text { of total } \\
\text { fleet }\end{array}$ & $\begin{array}{l}\text { Potential LNG } \\
\text { consumption } \\
\text { ('000 tonnes) }\end{array}$ \\
\hline Container & 3 & 21 & $0.48 \%$ & 251.8 to 609.3 \\
\hline Oil + Chemical tanker & 10 & 33 & $0.40 \%$ & 176.9 to 553.2 \\
\hline Bulk carrier & 3 & 3 & $0.06 \%$ & 24.6 \\
\hline Ferry \& ro-ro & 41 & 25 & $0.98 \%$ & 149.8 to 466.9 \\
\hline General cargo & 4 & 2 & $0.05 \%$ & 7.2 \\
\hline Liquefied gas tanker & 18 & 0 & $1.07 \%$ & 135.2 \\
\hline Service/tug/psv & 31 & 9 & $0.13 \%$ & 16.3 \\
\hline Cruise & 0 & 18 & $4.82 \%$ & 463.9 to $1,154.7$ \\
\hline Vehicle & 2 & 2 & $0.49 \%$ & 31.1 \\
\hline Other & 9 & 17 & $0.12 \%$ & 16.4 \\
\hline Total & $\mathbf{1 2 1}$ & $\mathbf{1 3 5}$ & $\mathbf{0 . 2 6 \%}$ & $\mathbf{1 , 2 7 3}$ to $\mathbf{3 , 0 1 5}$ \\
\hline
\end{tabular}

Source: DNV, ICCT, and author's calculations

\subsection{The key factors supporting the use of LNG}

The use of gas as a marine fuel is most likely where some or all of the following economic and legislative conditions are met:

- The vessels operate primarily or exclusively in areas subject to the IMO limit on sulphur of 0.1 per cent - the Emission Control Areas in N America and the Caribbean, and the Baltic and North $\mathrm{Sea}^{21}$. Whilst all vessels will be subject to the 0.5 per cent cap from 2020, the existing 0.1 per cent cap will make LNG an even more favourable option.

- The vessels are large and so fuel requirements are high - this enables fixed infrastructure costs to be more easily recovered and makes the vessels themselves a promising marketing prospect

- Fuel costs represent a relatively high proportion of total operating costs so any savings from a discount to gas oil will be material

- The vessels have regular and predictable journey patterns. This is important as it will be easier to plan for LNG refuelling on the assumption that facilities will not be as widespread as fuel oil, particularly in the early stages of development. It also implies high levels of utilization which will be important given the "perishable" nature of LNG.

- Operators are also owners of their vessels. This means that the benefits arising from the additional investment in LNG will be directly recouped by the owner rather than having to be reflected in higher charter rates which may be harder to recover - particularly if the shipping oversupply persists.

- Vessels follow routes that allow easy access to LNG fuelling facilities.

\footnotetext{
${ }^{21}$ http://www.imo.org/en/OurWork/Environment/SpecialAreasUnderMARPOL/Pages/Default.aspx
} 

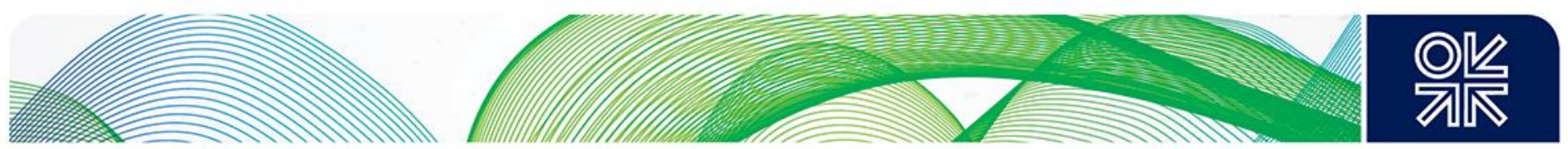

- There is a relatively high level of vessel turnover - in other words, a high frequency of new build or major re-fits. Whilst some vessels may be retro-fitted to use LNG, most are expected to be new builds.

- There is a relatively high level of auxiliary power demand and/or the vessel spends a relatively long time docked rather than at sea - a particular characteristic of cruise ships. Many ports are introducing rules on shore-to-ship power to reduce noise and environmental pollution, and studies have suggested that LNG presents a credible alternative to shore-based electricity (see Burgio and Pattichio, 2016)

- The sector is characterised by a number of large companies with extensive world-wide operations, for example container shipping and cruise lines. Larger companies are more likely to be prepared to make a strategic commitment to invest in a new fuel source such as LNG and will in turn represent a more attractive prospect for LNG marketers.

- $\quad$ There are high levels of government support for new investment favouring vessels using LNG.

These requirements are not "must haves" and their relative importance will vary. For example 50 per cent of the existing LNG vessels are operating in Norway. These ships represent a wide range of usage segments and, in this case, demonstrate the importance of state involvement which has been very proactive in the case of Norway ${ }^{22}$. Elsewhere there has been relatively limited direct state support for LNG shipping although in September 2017 Germany announced that Eur 278 million would be made available to 2020 to subsidise the conversion and construction of ocean-going vessels to $\mathrm{LNG}^{23}$, and South Korea has indicated it will provide around 10 per cent of the cost of new LNGfuelled bulk carriers ${ }^{24}$.

\subsection{The most promising sectors for LNG}

The conditions outlined in the previous section suggest that the most promising markets would be large container vessels, cruise ships, bulk carriers, and ferries together with most types of vessels spending all or most of their time operating in the Baltic/North Sea region or coastal North America. Other categories that might fit some of the foregoing conditions include tugs and dredgers in ports with LNG bunkering facilities. The main sectors are examined in more detail below.

\section{Container ships}

The container shipping sector is the largest in terms of fuel consumption and, arguably, the key bellwether for shipping. It is characterised by high and growing levels of concentration with the top ten carriers providing 75 per cent of shipping capacity in 2017 compared to 62 per cent in $2011^{25}$. Recent mergers include the combination of COSCO and China Shipping, Hapag Lloyd with United Arab Shipping, and Maersk's takeover of Hamburg Sud. The major players are shown in Table 8.

\footnotetext{
${ }^{22}$ See for example https://www.maritime-executive.com/article/norway-launches-green-shipping-project\#gs.VRfYtPI

${ }^{23}$ http://www.bmvi.de/SharedDocs/DE/Anlage/G/erster-foerderaufruf-Ing.pdf? blob=publicationFile

24 https://www.Ingworldnews.com/south-korea-confirms-push-to-revitalize-Ing-

bunkering/?utm source=emark\&utm medium=email\&utm campaign=daily-update-lng-world-news-2018-05-18\&uid=21190

${ }^{25}$ https://crucialperspective.com/global-container-shipping-outlook-2017/
} 
Table 8: Major container shipping lines

\begin{tabular}{|l|l|c|c|}
\hline Company & Domicile & $\begin{array}{l}\text { Market share (2017 } \\
\text { approx) }\end{array}$ & Number of vessels \\
\hline Maersk & Denmark & $16 \%$ & 621 \\
\hline MSC & Switzerland & $14.6 \%$ & 469 \\
\hline CMA CGM & France & $11.1 \%$ & 441 \\
\hline COSCO & China & $8.0 \%$ & 277 \\
\hline Hapag Lloyd/UASC & Germany & $7.9 \%$ & 236 \\
\hline NYK/MOL/K-Line & Japan & $7.1 \%$ & 243 \\
\hline Total & & $\mathbf{6 4 . 7 \%}$ & $\mathbf{2 , 2 8 7}$ \\
\hline
\end{tabular}

Source: UNCTAD 2017, $\mathrm{DHL}^{26}$

Despite the wave of mergers and consolidation plus the bankruptcy of Hanjin Shipping, over-supply persists. This means that the tendency for high levels of new vessel turnover has reduced with Platts reporting an orderbook-to-fleet ratio of 12 per cent in 2017 compared to a peak of 64 per cent in $2007^{27}$. The outlook for the sector is further clouded by concerns of a global trade war and a return to regionally based manufacturing.

Despite these negative factors the prospects for LNG shipping in this sector appear promising with the DNV monitor (2018) showing 21 vessels on order. These include those being built by French container shipping company CMA CGM which has announced that all of its new vessels will be equipped to run on LNG. Total has agreed to supply these ships with around 300,000 tonnes/year of LNG bunker fuel for ten years from 202028. In April 2018 Maersk said it had no plans to build any new container vessels though if it were to order new ships it "would definitely consider having LNG-fuelled ones"29. The company has ruled out sulphur scrubbers and LNG retro-fit for its existing vessels and will use ULSFO and MGO.

\section{Bulk Carriers}

Bulk carriers account for the vast majority of international seaborne trade in terms of tonnes loaded. The main commodities carried are iron ore (29 per cent of tonnes loaded in 2017), coal (23 per cent), grain (10 per cent), steel (8 per cent) and forest products (7 per cent) (UNCTAD 2017). In 2015 a 50,000 DWT LNG-fuelled carrier was commissioned to transport limestone for South Korean steelmaker POSCO. Larger (180,000 and 250,000 DWT) carriers are being designed by South Korean shipbuilders for deep water traffic such as iron ore shipments from Australia. Analysis of ICCT data indicates that the largest category of vessel consumes around 10,000 tonnes/year of LNG on an equivalent fuel basis.

\section{Oil, Gas, and Chemical tankers}

Tankers can include crude oil, oil products, chemicals, and gas - both LNG and LPG. Crude oil accounts for 60 per cent of shipments in terms of tonnes loaded in 2016 and oil products a further 28 per cent (UNCTAD 2017). Crude oil tankers may not however present a particularly promising market for LNG. The proportion of owner-operators is less than in some other sectors and the existing fuel supply arrangements are likely to be easily adapted to take lower sulphur fuel oil. For example,

\footnotetext{
${ }^{26}$ https://globalmaritimehub.com/wp-content/uploads/2018/05/dhl-ocean-freight-market-update-apr2018.pdf

${ }^{27} \mathrm{https}$ ://www.platts.com/latest-news/shipping/singapore/marine-fuel-sulfur-cap-to-raise-costs-ban-non-10384957

${ }^{28} \mathrm{http}$ ://www.Ingworldnews.com/cma-cgm-picks-Ing-fueled-engines-for-its- 
Teekay Shipping has indicated that it will be opting for a distillates-based solution for most of its fleet as retrofitting for sulphur scrubbers or LNG is too expensive ${ }^{30}$.

Although LNG tankers only account for 9 per cent of tanker shipments they are clearly important in this context due to the significant use of boil-off LNG as a fuel. As Rogers (2018) has recently pointed out, there has been a switch from traditional steam turbine propulsion to more efficient duel-fuel diesel engines (DFDE). A fully laden DFDE vessel can sail using only LNG from natural boil-off - though in order to optimize fuel consumption at the required vessel speed, a mix of LNG and fuel oil is usually consumed ${ }^{31}$.

\section{Cruise Ships}

The cruise shipping sector is not large in terms of its proportion of total vessels though individual ships are big with very high fuel consumption. For example, vessels in excess of 100,000 gross tonnes are calculated to have an average fuel consumption of around 60,000 tonnes/year of LNG on an equivalent fuel basis. Furthermore, the nature of cruise shipping means that operators are more exposed than most other sectors to scrutiny regarding their environmental footprint. As a consequence a number of operators have committed to using LNG and in March 201797 cruise ships were on order, of which 13 were to be dual-fuelled by LNG. This represented around 25 per cent of the gross tonnage on order in the cruise ship sector suggesting that larger ships are more favoured for LNG usage ${ }^{32}$.

The largest player in the sector, Carnival Cruise Lines, has seven LNG-fuelled cruise ships on order with delivery dates between 2020 and 2022. When operational, these could have a combined LNG fuel requirement of 300,000 tonnes of LNG per annum. It should be noted that the company has a total annual fuel usage of 3.2 million tonnes, 78 per cent of which was HSFO in 2016, and so could, alone, represent a very significant long-term market for $L_{N G}{ }^{33}$. In 2017 the company announced a framework agreement with Shell to supply LNG for its two new North American cruise ships to be delivered in 2020 and $2022^{34}$. Another important factor is that on average, a cruise ship spends around 40 per cent of its operating time in a port. Some ships are already using LNG for their energy requirements at this time ${ }^{35}$.

\section{Ferries and associated sectors}

With their regular and intensive journey patterns it is unsurprising that large ro-ro ferries, particularly those operating in ECAs such as the Baltic, have been early adopters of LNG as a fuel. A typical example is Fjord Line which has been operating LNG-fuelled ferries between Norway and Denmark since 2013. Other examples include the Megastar ferry sailing between Tallinn and Helsinki and US operator TOTE which has converted two of its ships to dual-fuel operation on LNG ${ }^{36}$.

A separate but similar category of ships is car carriers: these are a specialised form of ro-ro vessel that ship passenger cars. United European Car Carriers (UECC) operates two dual-fuelled car and truck carriers between Southampton and St. Petersburg. Another company, SIEM, is introducing two similar vessels in 2019 to ship VW cars from Europe to the USA.

\footnotetext{
${ }^{30}$ Singapore (Platts)--19 Mar 2018310 am EDT/710 GMT

${ }^{31}$ An example of this technology is the so-called MEGI engine (M-type, Electronically Controlled Gas Injection) - see https://www.flexlng.com/megi-propulsion/

${ }^{32} \mathrm{http}: / /$ www.passengership.info/news/view, Ing-rapidly-accelerates-in-cruise-sector $47023 . \mathrm{htm}$

${ }^{33}$ See http://carnivalsustainability.com/download-files/2016-carnival-sustainability-full.pdf p 80

${ }^{34} \mathrm{https}$ ://www.Ingworldnews.com/shell-to-fuel-carnivals-Ing-powered-cruise-

ships/?utm source=emark\&utm medium=email\&utm campaign=daily-update-Ing-world-news-2017-11-09\&uid=21190

${ }^{35}$ https://www.aida.de/en/aida-cruises/responsibility/aida-cares-2016/environment.33010.html

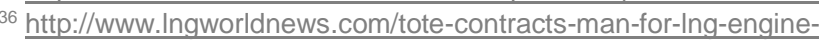

conversions/?utm source=emark\&utm medium=email\&utm campaign=daily-update-Ing-world-news-2017-11-10\&uid=21190
} 


\section{Forecast levels of LNG marine fuel usage}

This chapter provides a review of recent forecasts of LNG uptake in the marine sector and suggests some metrics for assessing these forecasts as the market evolves.

Earlier expectations of rapid growth in demand have not materialised. In 2012 DNV forecast that there would be over 1,000 LNG fuelled vessels by 2020. This was revised to between 400 and 600 in 2015 and the latest numbers suggest a fleet of below 300 by that time.

Lower oil prices and a slower than expected development of infrastructure were cited as the main reasons, though uncertainty over the evolving regulatory scene and the general downturn in new ship building are also likely factors. Indeed, the continued overhang of shipping capacity in most sectors could persist for some years ${ }^{37}$.

Forecasting LNG's share of the maritime market is complicated by the dynamics of overall demand and supply in the shipping sector. Global demand for shipping capacity is expected to grow though how this translates into fuel requirements will depend on how fuel efficiency (both through more efficient engines and larger ships) evolves and operational factors such as vessel utilisation and average speeds.

The situation is further complicated by tightening environmental regulations which will generate a range of responses. For existing vessels a range of abatement technologies are available and ship operators have the choice of switching fuels, installing scrubbers, or retrofitting to utilise LNG. As the 2020 deadline draws closer, more clarity on fuel availability options is starting to emerge. Platts reports $^{38}$ that a number of refiners have announced plans to produce 0.5 per cent sulphur fuels though arriving at a common standard for such fuels will be challenging and a range of products are likely to emerge.

As noted earlier, retrofitting for LNG is an unlikely option in the majority of cases. Consequently LNG demand in the sector will primarily be driven by new builds and so the number of LNG-fuelled vessels under construction is a useful leading indicator. Furthermore there are relatively few sectors where a switch to LNG will have a major impact of consumption volumes.

Table 9 shows how the number of LNG-fuelled vessels has evolved in recent years and as in Table 7, indicates a fleet of around 250 vessels which could equate to an annual consumption of between 1.2 and 3 million tonnes excluding consumption by LNG tankers. The total fleet continues to grow though the rate of growth shows no particular signs of accelerating.

Table 9: Number of LNG vessels in operation or ordered/under construction

\begin{tabular}{|l|c|c|c|c|c|c|}
\hline $\begin{array}{l}\text { LNG fuelled } \\
\text { vessels }\end{array}$ & $\mathbf{2 0 1 0}$ & $\mathbf{2 0 1 2}$ & $\mathbf{2 0 1 4}$ & $\mathbf{2 0 1 6}$ & $\begin{array}{c}\text { Jan } \\
\mathbf{2 0 1 8}\end{array}$ & $\begin{array}{c}\text { May } \\
\mathbf{2 0 1 8}\end{array}$ \\
\hline In operation & 21 & 35 & 56 & 77 & 119 & 122 \\
\hline $\begin{array}{l}\text { Ordered/under } \\
\text { construction }\end{array}$ & $\mathrm{n} / \mathrm{a}$ & $\mathrm{n} / \mathrm{a}$ & $\mathrm{n} / \mathrm{a}$ & 85 & 125 & 132 \\
\hline Total & $\mathbf{2 1}$ & $\mathbf{3 5}$ & $\mathbf{5 6}$ & $\mathbf{1 6 2}$ & $\mathbf{2 4 4}$ & $\mathbf{2 5 4}$ \\
\hline
\end{tabular}

Source: DNVi 
Table 10 shows some recent forecasts for LNG demand in the maritime sector. Again this excludes consumption by LNG tankers ${ }^{39}$.

Table 10: Forecasts of LNG consumption in the marine sector (mtpa)

\begin{tabular}{|l|c|c|c|c|}
\hline Source & $\mathbf{2 0 2 5}$ & $\mathbf{2 0 3 0}$ & $\mathbf{2 0 3 5}$ & $\mathbf{2 0 4 0}$ \\
\hline $\begin{array}{l}\text { IEA - Sustainable } \\
\text { Development }\end{array}$ & 11.6 & 18.8 & 26.8 & 37.0 \\
\hline IEA - New Policies & 23.9 & 29.7 & 36.2 & 41.3 \\
\hline ENGIE/PWC & & $24-30$ & & \\
\hline Lloyds Register & $8-30$ & $10-40$ & $15-45$ & $20-65$ \\
\hline
\end{tabular}

Source: IEA WEO 2017, PWC, Lloyds Register 2017

The broad consensus is of a demand level between 20 and 30 mtpa (28 and $40 \mathrm{bcm}$ ) per annum by 2030. The Lloyds Register study has a wider range which in part reflects a more extensive range of alternative scenarios in which hydrogen and biofuels also feature.

The forecast range for 2030 is a significant increase on today's levels and whilst it is quite feasible, it will require an increase in the trend of new builds. Table 11 shows that to reach 20 mtpa would require between 170 and 400 new shipping builds every year to 2030. An indication of how this level of activity compares with the number of new builds to date is shown in Figure 7. In this chart the "high consumption" assumption means that fewer ships need to be built to reach the same level of demand.

Figure 7: Number of LNG fuelled ships required to be built per annum to meet a demand level of $20 \mathrm{mtpa}$ LNGeq by 2030 for "average" and "high" consumption assumptions.

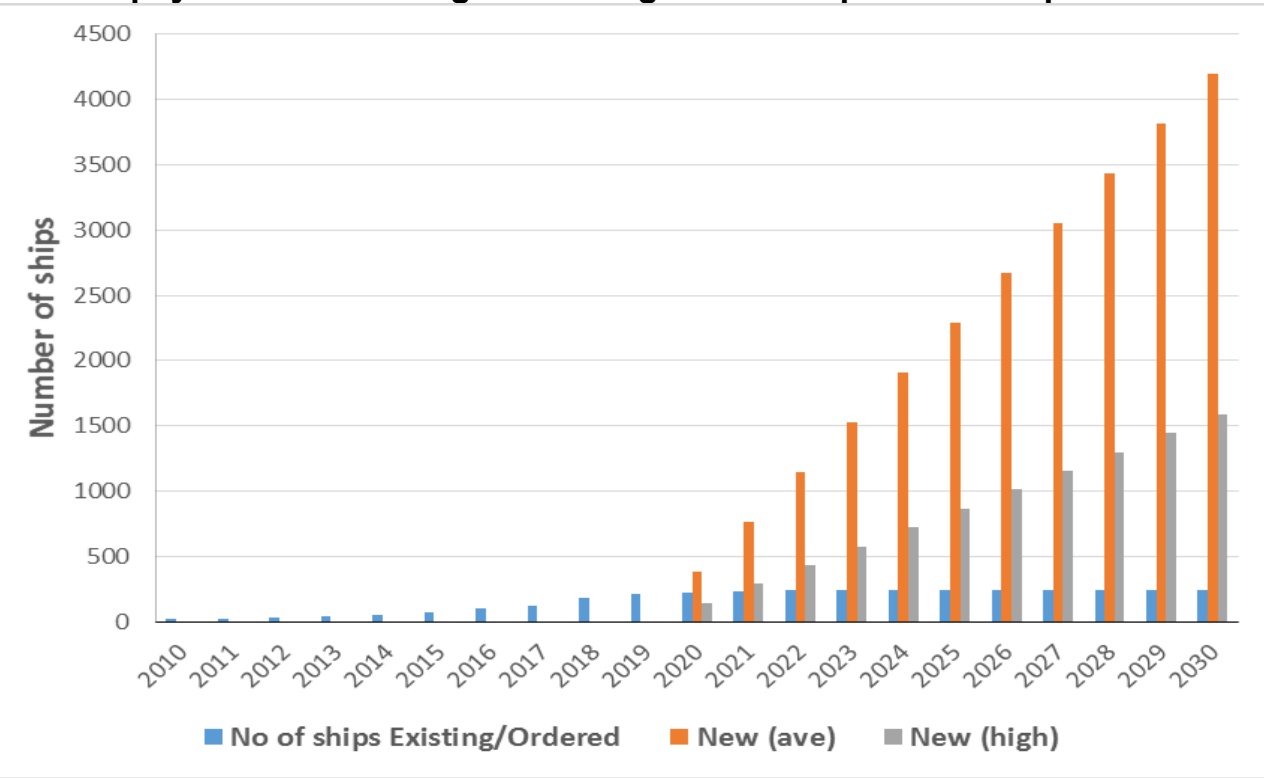

Source: DNV, ICCT and author's calculations

We have seen that the major consuming vessels are container ships and cruise lines. These are clearly good prospects for the LNG market and a relatively small number of vessels can make a big difference to the level of demand. If we assume that 80 per cent of the growth in demand comes from such large vessels, the approximate number required to be built over the coming decade is shown in

\footnotetext{
${ }^{39}$ The IEA forecasts do not explicitly exclude LNG carriers but this is assumed to be the case as the numbers quoted for LNG
} consumption in the sector in 2016 are zero. 
Table 11. So to reach 80 per cent of the forecast of 20 mtpa would require 23 new large cruise ships or 46 new large container ships to be built per annum. So an annual mix of, say, 5 new large cruise ships plus 10 new large container ships plus 15 other large vessels such as bulk carriers, ferries, etc. would meet the $20 \mathrm{mtpa}$ forecast. On balance the view at present is that the forecast range is reachable though challenging, and a demand level of around $15 \mathrm{mtpa}$ by 2030 may be more realistic. Furthermore given the lead times involved it will become apparent by the early 2020 s if the targets can be reached.

Table 11: LNG shipping new build requirement to meet 2030 forecasts of LNG consumption in the marine sector

\begin{tabular}{|l|l|l|}
\hline Demand level by 2030 & $\mathbf{2 0 ~ m t p a}$ & $\mathbf{3 0 ~ m t p a}$ \\
\hline Number of new builds per annum “average" consumption & 400 & 600 \\
\hline Number of new builds per annum "high" consumption & 170 & 255 \\
\hline Number of new large container ships built per annum* & 46 & 69 \\
\hline Number of new large cruise ships built per annum* & 23 & 34 \\
\hline
\end{tabular}

Source: Author's calculations

${ }^{*}$ Approximate number of new builds required to meet 80 per cent of the forecast level of demand

Some points to note:

- An additional 111 LNG-ready vessels are under construction. These could be readily adapted to use LNG so represent some potential upside.

- The forecasts exclude LNG tanker consumption (see below).

- Not all LNG demand will be met by the global LNG market as some will be sourced from locally liquefied gas as in Norway and Denmark.

As noted above the forecasts exclude LNG tanker consumption and post 2020 it may make commercial sense to increase the amount of fuel used as boil-off rather than high priced marine diesel. Table 12 presents some very approximate estimates of the potential size of this market by assuming that all LNG carriers were to switch exclusively to using LNG. Rogers (2018) has noted that the amount of fuel used per vessel will vary depending on the engine configuration (steam turbine or dual fuelled) and its average speed. Table 12 assumes that the LNG fleet grows in line with the IEA (2017) forecast and the proportion of DFDE vessels grows over time. It can be seen that if all LNG carriers were to use boil-off LNG only, this alone could represent around $17 \mathrm{mtpa}$ of demand by 2030 . An LNG-only fuel policy is, however, unlikely as the trade-offs between total fuel costs and cruising speed are likely to continue to make some oil product consumption economically attractive.

Table 12: Approximate fuel consumption for the LNG tanker fleet

\begin{tabular}{|c|c|c|c|}
\hline \multirow{2}{*}{ Year } & \multicolumn{2}{|c|}{ LNG tankers } & Total fuel consumed \\
in MT LNG
\end{tabular}

Source: Author's calculations derived from Rogers (2018) assuming: 55 Tonnes/day LNG equivalent for DFDE; 115 Tonnes/day LNG equivalent for ST - 300 days steaming /year at an average speed of 16.5 knots. 
There are also a number of factors that could reduce the longer term prospects for LNG. It is highly likely that fuel oil and gas oil will still play a major role in marine transport - particularly if there is no further tightening of the IMO restrictions. The industry is likely to recognize that the most effective way of removing sulphur is to do so at the refining stage and as more LSFO becomes available it could be very competitive with LNG.

Perhaps more importantly, LNG does not provide a long term and durable solution to low carbon shipping. The IMO (2014) reports that emissions from shipping were in the region of 1 Gt per annum in 2012. This equates to some 2.3 per cent of global emissions according to a report from Lloyds Register (2017) which notes that given the lack of progress in decarbonizing, marine transport is likely to become an increasing proportion of total global emissions over time. In April 2018 the IMO's Marine Environment Protection Committee (MEPC) set a target for reducing average $\mathrm{CO}_{2}$ emissions from international shipping by at least 50 per cent by $2050^{40}$. In commenting on this decision, Smith (2018) notes that from 2030 it is highly unlikely that new ocean-going vessels will be dependent on fossil fuels and new builds in the 2020s will need to be able to switch to non-fossil fuels later on. This knowledge will also impact on decisions made by insurers and shipping financiers and so could severely restrict the growth in LNG usage post 2030.

The levels of emissions growth could be mitigated and in time reduced through adopting a range of innovative technologies including batteries, ammonia, hydrogen, and biofuels. It is possible that in some markets LNG from biogas may feature, though there are a range of other bio fuel options in marine. These include biodiesel (from rapeseed oil or lignocellulose), bio fuel oil (from rapeseed oil), bio-hydrogen, and bio-methanol (both from lignocellulose or wood biomass).

LNG would still have a role to play though whether long term growth can be sustained is open to some doubt. Some players may see LNG as something of a cul-de-sac and decide to stick with oilbased fuels until a fully zero-carbon option becomes viable.

\section{LNG marine refuelling infrastructure}

Lack of re-fuelling infrastructure has frequently been identified as one of the major barriers to the development of this market. The capex requirements for bunkering are estimated by PWC (2018) at Eur 30 - 60 million for a port storage facility with a capacity of 6,000 to 15,000 cubic meters, and Eur $30-40$ million for a bunkering barge with a capacity of 3,000 to 10,000 cubic meters. This may restrict smaller ports from providing marine bunkering facilities though road-based refuelling would remain an option. The capital costs for road transportation are relatively lower at an estimated Eur 600,000 for a refuelling station.

These challenges of infrastructure development were often referred to as the "chicken-and-egg" problem whereby market growth was constrained by the lack of LNG re-fuelling infrastructure and this low growth was in turn inhibiting risk-based investments in the necessary infrastructure.

It is, however, arguable that this issue is unlikely to be a major constraint going forward. The evidence from Europe suggests that if there is sufficient market potential, infrastructure provision will be relatively rapid and will almost certainly exceed the build-up in demand capacity. This reflects:

- Decisions to switch vessels to LNG have a relatively long lead time and re-fuelling infrastructure can usually be made available relatively quickly, particularly where there are pre-existing LNG handling facilities in place.

\footnotetext{
${ }^{40}$ http://www.imo.org/en/MediaCentre/MeetingSummaries/MEPC/Pages/MEPC-72nd-session.aspx
} 
- The owners/operators of new-build LNG-fuelled ships are unlikely to commit without having a long term LNG supply contract in place. This would most probably cover both pricing and physical delivery so LNG suppliers will ensure there is the capacity to deliver at the agreed re-fuelling points.

- Facilities can be built up incrementally to match likely levels of demand. This may involve starting with road trailer refuelling and switching to bunkering vessels as the level of demand grows.

- Ports are anxious not to lose potential business and so will be keen to ensure they have some LNG capacity even if it is underused in the short term. The Port of Rotterdam is one of many that are keen to stress its willingness and capability to handle LNG re-fuelling ${ }^{41}$.

- Support from governments to invest as well as requirements from some authorities to provide infrastructure as in the case of the EU Blue Corridors project ${ }^{42}$.

The evidence from Europe supports this contention. GIE maintains a small-scale LNG infrastructure database ${ }^{43}$ listing existing and planned facilities such as bunkerships, small-scale liquefaction plants, and satellite LNG storage facilities. The database illustrates that the presence of large-scale LNG import terminals is an important factor in underpinning the development of re-fuelling infrastructure. At the end of 2017, 75 per cent of operational small-scale units were in countries with major regasification terminals (GIE, 2018). Those countries with such facilities (for example France, Italy, Spain, and the UK) saw an increase in small-scale facilities of 133 per cent from June 2016 to end 2017. Table 13 summarises the latest position for Europe.

Table 13: LNG refuelling infrastructure in Europe

\begin{tabular}{|l|c|c|c|}
\hline Facility & Existing & $\begin{array}{c}\text { Under } \\
\text { construction }\end{array}$ & Planned \\
\hline $\begin{array}{c}\text { LNG terminals with: } \\
-\quad \begin{array}{l}\text { Reloading small } \\
\text { scale LNG }\end{array}\end{array}$ & 15 & 10 & 12 \\
\hline$-\quad$ Truck loading & 25 & 7 & 7 \\
\hline$\quad$ Rail loading & - & - & 5 \\
\hline Liquefaction plants & 21 & n.a. & 4 \\
\hline $\begin{array}{l}\text { Bunkering facilities for } \\
\text { vessels }\end{array}$ & 39 & 12 & 12 \\
\hline Bunker ships & 11 & 1 & 6 \\
\hline $\begin{array}{l}\text { Refuelling stations for } \\
\text { trucks }\end{array}$ & 167 & 8 & 63 \\
\hline Satellite LNG Storage & $>1000$ & n.a. & n.a. \\
\hline
\end{tabular}

Source: GIE

One interesting aspect of infrastructure development is the construction of what might be termed market-based liquefaction facilities whereby grid gas is liquefied specifically to meet transport 
demand. Some of this plant was built some time ago as peak shaving facilities, though more recent examples include:

- Norway - There are seven liquefaction plants including the 300,000 metric ton/yr plant operated by Skangas in Risavika and the 200,000 metric ton/yr plant operated by Gasnor in Snurrevarden (Karmøy).

- In Denmark, Unioil has announced plans to build a liquefaction plant using biogas at the port of Frederikshavn ${ }^{44}$.

- The port of Jacksonville is building two small-scale liquefaction facilities capable of producing 320,000 gallons/day of LNG.

- American Gas \& Technology aims to provide dedicated LNG re-fuelling stations for commercial fleet operators using gas from a local distribution network. Customers will be required to commit to a long-term take or pay agreement priced at a discount to the market price for diesel which will include the capital and operating costs of the facility and the cost of vehicle conversion to LNG ${ }^{45}$.

Developing infrastructure will be a key component in enabling land-based applications for LNG and this is briefly considered in the next chapter.

\section{LNG in land-based transport}

This aspect, along with prospects for CNG, will be covered in more detail in a separate paper to be published later in 2018. This section provides a very brief overview. In many countries, land-based usage of LNG in transport will be linked to developments in the marine sector as the cryogenic supply chain evolves. For example, in the early stages of demand build-up many marine users will refuel using LNG road tankers and this will enhance the development of road refuelling infrastructure. In most countries land-based LNG in transport is unlikely to be as significant as marine, at least in volume terms. It is, however, already very significant in China (Weigou, 2017) and India could also grow to be a substantial market.

In common with marine applications, LNG trucks have a number of advantages over alternative fossil fuels. According to Scania, its trucks with an LNG powertrain emit up to 20 per cent less $\mathrm{CO}_{2}$ than comparable diesel engines and this reduction could be as high as 90 per cent if biogas is used. In addition these vehicles emit 95 per cent fewer nitrogen oxides $\left(\mathrm{NO}_{\mathrm{x}}\right)$ and almost no particulate matter. Furthermore noise levels are around 50 per cent lower than diesel engine trucks.

In Europe, vehicle availability has been something of a constraint in some countries but this issue now seems to have been largely solved. There are now three major original equipment manufacturers (OEMs): Volvo, SCANIA, and Iveco producing LNG-fuelled HGVs, and Volvo predicts that 20 per cent of all new HGVs will be LNG-fuelled by the early $2020 \mathrm{~s}^{46}$. Some large operators have made major commitments. The Jost Group, a major European transport and logistics company, will acquire 500 LNG-fuelled HGVs from Iveco between 2018 and 2020. The company aims to have 35 per cent of its 1,400 vehicle fleet running on $L N G$ and is also investing in $L N G$ refuelling facilities at its three major operational hubs ${ }^{47}$. Belgian transport company Remitrans plans to have 30 per cent of its fleet using LNG by 2019 and eventually all of its trucks will be LNG-fuelled ${ }^{48}$.

\footnotetext{
${ }^{44} \mathrm{http}: / /$ www.bunkerindex.com/news/article.php?article_id=18763

${ }^{45} \mathrm{http}: / /$ www.rueone.com/images/marketing/RueOne-AGT-Overview.pdf

${ }^{46}$ https://www.Ingworldnews.com/volvos-fm-Ing-truck-to-fuel-at-calors-donington-

station/?utm source=emark\&utm medium=email\&utm campaign=daily-update-Ing-world-news-2018-04-16\&uid=21190

${ }^{47}$ http://www.Ingworldnews.com/iveco-books-order-for-500-Ing-fueled-

trucks/?utm source=emark\&utm medium=email\&utm campaign=daily-update-lng-world-news-2017-10-23\&uid=21190

${ }^{48} \mathrm{https}$ ://www.Ingworldnews.com/liqal-to-build-Ing-fueling-station-for-

remitrans/?utm source=emark\&utm medium=email\&utm campaign=daily-update-Ing-world-news-2018-03-23\&uid=21190
} 
In the US there are nearly 2,000 natural gas refuelling stations, mainly CNG with around 180 LNG stations operating or planned ${ }^{49}$. There are a range of state based incentives including grants, fuel tax reductions, and reduced license fees for NGVs. A number of large hauliers have started to shift significantly towards LNG and CNG. These include global logistics player UPS which now operates 4,400 natural gas vehicles and a network of fuelling stations ${ }^{50}$.

In China, the government is actively supporting NGVs through production subsidies, R\&D funding, and by waiving highway tolls. It is targeting an increase from 5.2 million vehicles in 2015 to 10.5 million by 2020 although there are questions over gas availability and price competitiveness that may restrict that target (Sen et al, 2017).

There are varying views on the implications of land-based transport applications for global gas demand. Shell, in its 2018 LNG Outlook, expects demand for gas in transport (land and sea) to reach approximately $100 \mathrm{bcm}$ by 2035 accounting for 7 per cent of the growth in gas demand over this period $^{51}$. The IEA (2017) forecasts that demand for gas (LNG and CNG) in land transport could be as high as $125 \mathrm{bcm}$ in 2030 and $180 \mathrm{bcm}$ in 2040 under its New Policies Scenario. In this scenario it expects that China, the US, and India will the main sources of growth with gas used both in freight and, most notably in India, passenger vehicles.

\section{Conclusions}

There is no doubt that the growing level of interest displayed in LNG as a marine fuel is justified. The level of usage is certain to grow, driven by both environmental restrictions and economic attractiveness. There is, however, less certainty over the pace and scale of demand growth. This in part is due to the relatively poor data quality on marine fuel usage but primarily a reflection on the still early nature of market development and uncertainties over alternative fuel options.

Experience to date suggests that the adoption of LNG is most likely where some or all of the following conditions are present:

- The vessels operate primarily or exclusively in areas subject to the IMO limit on sulphur of 0.1 per cent

- The vessels are large and fuel costs are a high proportion of operating costs

- The vessels have regular and predictable journey patterns

- Operators are also owners of their vessels

- Vessels follow routes that allow easy access to LNG fuelling facilities

- There is a relatively high level of vessel turnover - in other words, a high frequency of new build or major re-fits

- There is a relatively high level of auxiliary power demand.

- There are high levels of government support for new investment favouring LNG.

\footnotetext{
${ }^{49}$ https://www.ngvamerica.org/

${ }^{50} \mathrm{https://pressroom.ups.com/pressroom/ContentDetailsViewer.page?ConceptType=PressReleases \& id=1489579573572-162}$

${ }^{51} \mathrm{https}: / /$ www.shell.com/energy-and-innovation/natural-gas/liquefied-natural-gas-Ing/lng-

outlook/jcr_content/par/textimage_864093748.stream/1519645795451/d44f97c4d4c4b8542875204a19c0b21297786b22a900 ef8c644d07d74a2f6eae/shell-Ing-outlook-2018-presentation-slides.pdf
} 

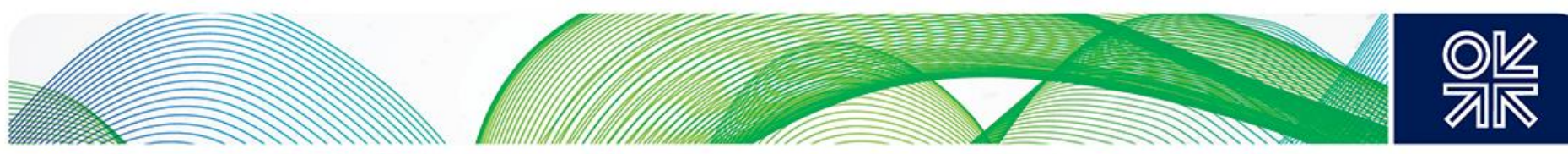

These conditions indicate that there are some shipping sectors that are likely to be more promising for LNG than others. For example ro-ro ferries, cruise ships, bulk carriers, large container vessels, and, of course, LNG tankers.

Because of the costs of retrofitting, most LNG-fuelled ships will be newly built and owners/operators are unlikely to commit without concluding a long-term supply contract covering both pricing and physical delivery. LNG suppliers which are prepared to conclude such contracts will provide an important stimulus to the market. The lead times involved and the relatively low capital cost of infrastructure suggest that refuelling capacity is unlikely to be a constraint.

Most forecasts suggest that global demand should be in the range of 25 to $30 \mathrm{mtpa}$ of LNG by 2030 . This would require that, very approximately, between 2,000 and 6,000 new or converted vessels would be fuelled by LNG by then. Reaching a fleet of this size would appear challenging at the present level of new builds. It is considered, therefore, that a demand level of around $15 \mathrm{mtpa}$ by 2030 is a more realistic prospect. This outlook could change rapidly, however, if a number of large shipping companies were to commit to LNG. All of these forecasts exclude LNG carriers. If all of these were to switch exclusively to LNG, this alone could represent around $17 \mathrm{mtpa}$ of demand by 2030.

A number of potential barriers to uptake remain. These include the continuing surplus of shipping capacity in many sectors, uncertainty over future prices for oil and gas, and logistical challenges. Perhaps most importantly though, gas is not a zero carbon solution. Given the continuing pressure on the marine sector to improve its environmental footprint, ship owners may be tempted to wait for new lower carbon options such as batteries and biofuels to emerge. The use of biogas as a source for LNG is a possibility although there are probably more realistic biofuel options that would be preferred. Where there are examples of biogas in the transport supply chain, for example CNG fuelled cars and trucks, significant state support is necessary.

LNG is an answer to some of the problems facing marine transport. It is too early to say if it is the answer. To date only a small number of major shipping operators have made a clear commitment to new build LNG-fuelled ships. If other large companies start to follow their lead this will be a key indication that LNG will be a significant fuel in marine transport for the next twenty years. 


\section{References}

Anderson, M., Salo, K. \& Fridell, E. (2015), Particle - and Gaseous Emissions from an LNG Powered Ship. Environmental Science \& Technology, 49(20), pp.12568-12575. DOI: 10.1021/acs.est.5b02678

Bros T. (2018), OIES Quarterly Gas Review https://www.oxfordenergy.org/wpcms/wpcontent/uploads/2018/03/Quarterly-Gas-Review-1.pdf

Burgio C. and Patticchio N. (2016), Electric Shore Power v LNG in the port of Civitavecchia, Presentation made at Trieste on 10 March 2016 http://www.marefvg.it/it/download/2-2-burgio---shorepower-vs-Ing.pdf

DNV (2017), Future Role of Gas from a Regulatory Perspective - Outlook and Recommendations, Report for CEER prepared by DNV-GL https://www.dnvgl.com/publications/study-on-the-future-roleof-gas-from-a-regulatory-perspective-- 119855

DNV (2018), LNG status update, May 2018 https://www.dnvgl.com/maritime/mydnvgl-serviceoverview/lng-intelligence-Ingi/

GIE (2018), Small-Scale LNG database 2018

http://www.gie.eu/index.php/publications/gie/doc download/27063-press-release-gie-releases-thesmall-scale-Ing-database-2018

GIIGNL (2018), The LNG Industry, Annual report 2018

https://giignl.org/sites/default/files/PUBLIC AREA/Publications/rapportannuel-2018pdf.pdf

Le Fevre C. (2014), The Prospects for Natural Gas as a Transportation Fuel in Europe, OIES Working Paper No. 84, 3 March 2014 Oxford https://www.oxfordenergy.org/wpcms/wp-

content/uploads/2014/03/NG-84.pdf

Olmer et al (2017), Greenhouse gas emissions from global shipping, 2013-2015, The International Council on Clean Transportation https://www.theicct.org/publications/GHGemissions-global-shipping-2013-2015

IMO (2015), Third IMO GHG Study, The International Maritime Organization http://www.imo.org/en/OurWork/Environment/PollutionPrevention/AirPollution/Documents/Third\%20Gr eenhouse\%20Gas\%20Study/GHG3\%20Executive\%20Summary\%20and\%20Report.pdf

Lloyds Register (2014), Global Marine Fuel Trends 2030 https://www.Ir.org/en/insights/global-marinetrends-2030/global-marine-fuel-trends-2030/

Lloyds Register (2017), Low Carbon Pathways 2050 http://www.umas.co.uk/LinkClick.aspx?fileticket=EJ9kSG7Yues\%3d\&portalid=0

PWC (2017), Small going big: Why small-scale LNG may be the next big wave https://www.strategyand.pwc.com/media/file/Small-going-big.pdf 
Ricardo (2017) A review of the NAEI shipping emissions: Methodology - Final report. Report for the Department for Business, Energy \& Industrial Strategy PO number 1109088, December 2017 https://ukair.defra.gov.uk/assets/documents/reports/cat07/1712140936 ED61406 NAEI shipping re port 12Dec2017.pdf

Rogers H. (2018), The LNG Shipping Forecast: costs rebounding, outlook uncertain, OIES Energy Insight: 27 https://www.oxfordenergy.org/wpcms/wp-content/uploads/2018/02/The-LNG-ShippingForecast-costs-rebounding-outlook-uncertain-Insight-27.pdf

Sen et al (2017), Anupama Sen, Michal Meidan and Miswin Mahesh, Gasoline Demand in Transport in Non-OECD Asia, OIES Energy Insight, November 2017 https://www.oxfordenergy.org/wpcms/wpcontent/uploads/2017/11/Gasoline-Demand-in-Transport-in-Non-OECD-Asia-Insight-22.pdf

Sharples J., Cryogenic Supply Chains and LNG in Transportation, OIES Working Paper, Forthcoming

Smith T, (2018), The IMO's 2018 climate agreement explained, UCL 2018 https://gmn.imo.org/wpcontent/uploads/2018/05/IMOs-2018-climate-agreement-explained-a-UCL-document.pdf

Thinkstep (2017), Greenhouse Gas Intensity from Natural Gas in Transport, A study for the Natural Gas Vehicles Association http://ngvemissionsstudy.eu/

Thomson et al (2015), Thomson H., Corbett J., Winebrake J., Natural gas as a marine fuel in Energy Policy Vol 87, September, 2015

https://www.sciencedirect.com/science/article/pii/S0301421515300665?via\%3Dihub

UNCTAD (2017), Review of Maritime Transport, 2017 UN Conference on Trade and development, October 2017 http://unctad.org/en/pages/PublicationWebflyer.aspx?publicationid=1890

Wartsila (2018), Developer's Guide to small-scale LNG terminals

https://www.wartsila.com/docs/default-source/power-plants

documents/downloads/brochures/developers-guide-to-small-scale-Ing-terminal.pdf

Weiguo Shan (2017) "Golden Era" is back to China? Presentation to IGU Chengdu, Nov 1. 2017, CNPC Economics \& Technology Research Institute

Young P., Middle East Poised to Join the Ranks of Trading Hubs, article in Oxford Energy Forum, May 2018: ISSUE 113 https://www.oxfordenergy.org/wpcms/wp-content/uploads/2018/05/OEF113.pdf 


\section{Glossary}

Note: Some of the terms are used in the gas industry and others in the marine sector

- Bcm: one billion cubic metres.

- Bcma: one billion cubic metres per annum.

- Biogas: gas produced from the anaerobic digestion of organic matter such as animal manure, sewage, and municipal solid waste.

- Biomass: any organic material which has stored sunlight in the form of chemical energy. As a fuel it may include wood, wood waste, straw, manure, sugarcane, and many other by products from a variety of agricultural processes.

- Biomethane: biogas which is upgraded to vehicle fuel quality.

- Bulk vessel: description of vessels transporting large cargo quantities, including coal, iron ore, steel, corn, gravel, oil, gas, etc.

- Bunker: fuel for vessels.

- CNG: compressed natural gas, made by compressing natural gas (which is mainly composed of methane [CH4]), to less than 1 per cent of the volume it occupies at standard atmospheric pressure. It is a fossil fuel substitute for gasoline (petrol), diesel, or propane/LPG.

- $\mathrm{CO}_{2}$ : carbon dioxide, the principal greenhouse gas

- Conventional Gas: natural gas produced from an underground reservoir other than shale gas, tight gas, or coal bed methane.

- DWT: Dead Weight Tonnage - the total weight of a ship's cargo, fuel, etc.

- ECA: Emission Control Area

- FOB: Free On Board (with regard to bunker or LNG prices)

- FOC: Fuel Oil Consumption

- FSPO: Floating Storage, Production and Offloading

- GT: Gross Tonnage (an index of ship's overall internal volume)

- GHG: Greenhouse Gas

- GT: Gas Transporter

- HH Henry Hub: a US physical trading hub

- IEA: International Energy Agency

- ICCT: International Council on Clean Transportation

- IMO: International Maritime Organization (www.imo.org)

- ISO: International Organization for Standardization

- JRC: Joint Research Centre (of the EU Commission)

- LHV: Lower Heating Value ('Lower" indicates that the heat of condensation of water is not included)

- LBM: Liquefied Biomethane

- LNG Terminal: Facility for importing ship-borne LNG. Normally the LNG is stored at the terminal before regasification and injection into the transmission system.

- LNG: Liquefied natural gas, natural gas liquefied by cooling to minus 162 degrees Centigrade

- $L_{\text {LNG }}$ : Fuel consumption expressed in tonnes of LNG whereby 1 tonne of LNG contains 52 MMbtu, 1 tonne of fuel oil $40.7 \mathrm{Mmbtu}$ and 1 tonne of marine gasoil $43.3 \mathrm{MMbtu}$

- LNGs or LNG storage (also called LNG Peak Shaver): a gas storage facility which provides high output of natural gas albeit for a short duration. The facility extracts natural gas from the transmission grid, liquefies it and stores it in an insulated vessel. When gas is required to meet peak loads the LNG is regasified and injected into the transmission system. Note this definition does not include storage tanks at LNG regasification terminals.

- MARPOL: International Convention for the Prevention of Pollution from Ships, 1973, as modified by the Protocol of 1978 .

- Mcm: million cubic metres

- $\mathrm{mcm} /$ day: million cubic metres per day.

- MDO: Marine Diesel Oil 
- Methane fuels: common name for CNG and Compressed Biomethane, LNG and Liquified Biomethane, all of them are with methane content over 90 per cent, up to 99 per cent. The methane content depends from the country specific gas quality standards.

- Methane slip: $\mathrm{CH} 4$ emissions from the dispensing or incomplete combustion of natural gas in transportation.

- MGO: Marine Gas Oil

- MMBtu: Million British Thermal Unit, $1 \mathrm{MMBtu}=293 \mathrm{kWh}=1.055 \mathrm{MJ}$

- MT: Million Tonnes

- MTPA: Million Tonnes per annum

- MTOE: Million Tonnes of oil equivalent

- $\mathrm{N}_{2} \mathrm{O}$ : 'Nitrous oxide, a very potent greenhouse gas

- NBP: the UK's National Balancing Point: a virtual point (hub) in the National Transmission System where gas trades are deemed to occur. It is also used as shorthand for the UK spot gas price.

- NOx: A mixture of various nitrogen oxides as emitted by combustion sources

- OEM: Original Equipment Manufacturer: for example a large vehicle or engine manufacturer such as Ford or Rolls Royce

- Oil Indexed Gas Prices: gas prices within long term contracts which are determined by formulae containing rolling averages of crude oil or defined oil product prices.

- OSV: Offshore Supply Vessel (often used in the US instead of PSV)

- PM: particulate matter - microscopic emissions from diesel engines that have been shown to cause breathing difficulties and to have a carcinogenic effect

- Product Tanker: Tanker vessel with coated tanks used to transport refined oil products

- PSV: Platform Supply Vessel

- SIGTTO: Society of International Gas Tanker and Terminal Operators

- TPS: Bunkering from storage Tank via Pipeline to Ship

- STS: Ship To Ship (LNG bunkering concept)

- TEU: twenty-foot equivalent units - the standard dimensions of carrying capacity for container ships

- TPA: Third Party Access - in the context of storage there is regulated - rTPA - or negotiated third party access - nTPA.

- TTF: Title Transfer Facility - the Dutch trading hub

- TTS: Truck To Ship (LNG bunkering concept)

- TTW: Tank-To-Wheels, description of the burning of a fuel in a vehicle

- TWh: A unit of energy equivalent to a Terawatt of power over the duration of one hour.

- UKCS: The UK Continental Shelf

- ULSFO: Ultra low sulphur fuel oil.

- UNCTAD: United Nations Conference on Trade and Development

- WTT: Well-To-Tank: the cascade of steps required to produce and distribute a fuel (starting from the primary energy resource), including vehicle refueling

- WTW: Well-To-Wheels or Well-To-Wake: the integration of all steps required to produce and distribute a fuel (starting from the primary energy resource) and use it in a vehicle (Well-ToWheels) or ship (Well-To-Wake) 


\section{Appendix A}

\section{Average fuel consumption numbers for major shipping categories}

The following calculations have been derived from the ICCT tables available at https://www.theicct.org/sites/default/files/Supplemental_material_final_vf\%28locked\%29.xlsx

Table A1: Container ships

\begin{tabular}{|l|c|c|c|}
\hline Category in TEU & Number of vessels & $\begin{array}{l}\text { Total fuel } \\
\text { consumption in MT } \\
\text { LNGeq }\end{array}$ & $\begin{array}{l}\text { Average } \\
\text { consumption in } \\
\text { Tonnes of LNGeq }\end{array}$ \\
\hline $0-999$ & 854 & 2.5 & 2877 \\
\hline $1,000-1,999$ & 1,250 & 6.9 & 5486 \\
\hline $2,000-2,999$ & 638 & 5.1 & 7983 \\
\hline $3,000-4,999$ & 875 & 11.1 & 12630 \\
\hline $5,000-7,999$ & 600 & 10.3 & 17146 \\
\hline $8,000-11,999$ & 548 & 10.6 & 19359 \\
\hline $12,000-14,500$ & 176 & 4.2 & 23935 \\
\hline$>14,500$ & 68 & 2.0 & 29151 \\
\hline Total & 5,009 & 52.5 & $\mathbf{1 0 , 4 9 1}$ \\
\hline
\end{tabular}

Table A2: Bulk carriers

\begin{tabular}{|l|c|c|c|}
\hline \multicolumn{1}{|c|}{ Category in DWT } & Number of vessels & $\begin{array}{c}\text { Total fuel } \\
\text { consumption in MT } \\
\text { LNGeq }\end{array}$ & $\begin{array}{c}\text { Average } \\
\text { consumption in } \\
\text { Tonnes of LNGeq }\end{array}$ \\
\hline $0-9,999$ & 765 & 0.7 & 886 \\
\hline $10,000-34,999$ & 2,060 & 5.0 & 2,409 \\
\hline $35,000-59,999$ & 3,278 & 11.0 & 3,346 \\
\hline $60,000-99,999$ & 2,921 & 13.4 & 4,576 \\
\hline $100,000-199,999$ & 1,212 & 9.1 & 7,548 \\
\hline $200,000-+$ & 414 & 4.5 & 10,901 \\
\hline Total & $\mathbf{1 0 , 6 5 0}$ & $\mathbf{4 3 . 6}$ & $\mathbf{4 , 0 9 4}$ \\
\hline
\end{tabular}




Table A3: Oil tankers
\begin{tabular}{|l|c|c|c|}
\hline Category in GT & Number of vessels & $\begin{array}{l}\text { Total fuel } \\
\text { consumption in MT } \\
\text { LNGeq }\end{array}$ & $\begin{array}{l}\text { Average } \\
\text { consumption in } \\
\text { Tonnes of LNGeq }\end{array}$ \\
\hline $0-4,999$ & 2,459 & 2.7 & 1,114 \\
\hline $5,000-9,999$ & 678 & 1.3 & 1,858 \\
\hline $10,000-19,999$ & 195 & 0.6 & 3,046 \\
\hline $20,000-59,999$ & 602 & 3.1 & 5,068 \\
\hline $60,000-79,999$ & 380 & 2.5 & 6,547 \\
\hline $80,000-119,999$ & 917 & 6.5 & 7,058 \\
\hline $120,000-199,999$ & 507 & 4.8 & 9,540 \\
\hline$>200,000$ & 657 & 10.1 & 15,429 \\
\hline Total & 6,395 & 31.6 & 4,941 \\
\hline
\end{tabular}

Table A4: Cruise ships

\begin{tabular}{|l|c|c|c|}
\hline Category in GT & Number of vessels & $\begin{array}{l}\text { Total fuel } \\
\text { consumption in MT } \\
\text { LNGeq }\end{array}$ & $\begin{array}{l}\text { Average } \\
\text { consumption in } \\
\text { Tonnes of LNGeq }\end{array}$ \\
\hline $0-1,999$ & 155 & 0.2 & 1,111 \\
\hline $2,000-9,999$ & 63 & 0.1 & 1,996 \\
\hline $10,000-59,999$ & 101 & 1.4 & 13,770 \\
\hline $60,000-99,999$ & 96 & 4.3 & 44,420 \\
\hline $100,000-+$ & 62 & 3.7 & 59,163 \\
\hline Total & $\mathbf{4 7 7}$ & $\mathbf{9 . 6}$ & $\mathbf{2 0 , 1 2 5}$ \\
\hline
\end{tabular}

